Open Access

\title{
Just like a woman? New comparative evidence on the gender income gap across Eastern Europe and Central Asia
}

Niels-Hugo Blunch ${ }^{1,2}$ (D)

Correspondence: blunchn@wlu.edu ${ }^{1}$ Department of Economics, Washington and Lee University, Lexington, VA 24450, USA

${ }^{2}$ IZA, Bonn, Germany

\begin{abstract}
I examine the incidence and determinants of the gender income gap in Kazakhstan, Macedonia, Moldova, Serbia, Tajikistan, and Ukraine using recent household data based on an identical survey instrument across countries. Four main results are established, using a range of estimators, including OLS, interval regression, and quantile regression: (1) the presence of a substantively large gender income gap (favoring males) in all six countries; (2) some evidence of a gender-related glass ceiling in some of these countries; (3) some evidence that endowments diminish the income gaps, while the returns to characteristics increase the gaps; and (4) while observed individual characteristics explain a part of the gaps, a substantial part of the income gap is left unexplained. In sum, these results are consistent with the presence of income discrimination towards females but at the same time also point towards the importance of continued attention towards institutions and economic policy for decreasing the gender income gap in these former formally gender neutral economies - notably through attention towards the maternity and paternity leave system, as well as public provision of child care.
\end{abstract}

JEL Classification: J16, J31, J7

Keywords: Gender, Income gap, Oaxaca-blinder decomposition, Detailed decomposition, Maternity/paternity leave policies, Eastern Europe and Central Asia

\section{Introduction}

Despite a decline in recent years, the gender gap in income (or earnings or wages) undoubtedly is one of the most persistent regularities in the labor market. Most of the available evidence, however, is for Western economies, especially the USA (Albrecht et al. 2003; Altonji and Blank 1999; Blau 1998; Blau and Kahn 1992, 1996, 1997, 2000, 2003; Cho and Cho 2011), though evidence for the former socialist regimes of Eastern Europe and Central Asia is starting to emerge (Brainerd 2000; Grajek 2003; Hunt 2002; Orazem and Vodopivec 2000).

This decline notwithstanding the inequality of women in the labor market is important for several reasons. Most notably, the lack of gender equality in the labor market likely is associated with economic dependence of women more generally, leading to lack of influence in decision making-including investments in health and education for the household, including children, and greater susceptibility to violence in the home. Could the

(c) The Author(s). 2018 Open Access This article is distributed under the terms of the Creative Commons Attribution 4.0 International License (http://creativecommons.org/licenses/by/4.0/), which permits unrestricted use, distribution, and reproduction in any medium, provided you give appropriate credit to the original author(s) and the source, provide a link to the Creative Commons license, and indicate if changes were made. 
position of women in the labor market instead be improved, these outcomes will likely be reversed, also.

In light of these considerations, this paper provides a thorough examination of the incidence and nature of the gender income gap across six former socialist countries from Eastern Europe and Central Asia: Kazakhstan, Macedonia, Moldova, Serbia, Tajikistan, and Ukraine. Again, while evidence on the gender gap in transition countries in general is starting to emerge, it seems fair to say that it is still the case that little or no systematic data collection and reporting has been taking place, so far-thus mostly resulting in only fragmented data analysis for individual countries, at best. Contrary to this, the data examined here originate from a recent UNDP/UNICEF survey which was conducted using identical questionnaires for all six countries, thus greatly facilitating such comparative analysis as is pursued here. Indeed, examining the gender income gap for a collection of transition countries using comparable survey instruments is likely to increase our understanding of the gender income gap in transition countries in general. This includes the extent to which income-based gender discrimination seems to be present, as well as the extent to which the drivers of a possible gender income gap differs across countries-thus ultimately also serving as inputs for policy makers to help better address such gender-based discrimination by implementing appropriate gender-targeted policies.

The analysis starts out by establishing the prevalence of a substantively large gender income gap (favoring males) in all six countries, then goes on to estimate Mincer-type income regressions, and finally decomposes this gap using several alternative twofold and threefold decompositions to test the robustness of results-for both aggregate and detailed gender income gap decompositions, where the latter decomposes the origins of the gender income gap into its component part in terms of (groups of) specific explanatory variables such as education and sector of occupation.

The remainder of this paper is structured as follows. First, the next section reviews recent developments in the six countries examined here to provide a foundation for the subsequent analysis, including a context in which to both perform the analysis and interpret the subsequent results. Section 3 presents the data, discusses the construction of the dependent and explanatory variables, and estimates the raw gender income gaps. This is followed, in Section 4, by a discussion of the estimation strategy and related issues. Section 5 presents the main results while, finally, Section 6 concludes, discusses policy implications, and provides directions for further research.

\section{Recent developments in the six countries under study with a focus on the labor market and gender-related developments}

This section first gives a brief historical background and motivation for studying gender and labor market issues in the six former socialist countries of Eastern Europe and Central Asia examined here and then goes on to present recent economic trends in these countries.

\subsection{Gender and the labor market in transition economies}

Across the former socialist countries in Eastern Europe and Central Asia, wages were mostly assigned by central planners by establishing an occupational wage scale within each industry - and wages were then set as a multiple of the wage of the lowest-grade occupation, the base wage (Brainerd 2000). Another noteworthy feature of the wage setting scheme in 
most former socialist countries is the extreme compression of wage scales-so that top managers, for example, would rarely earn more than five times as much as the average manual worker, whereas the same ratio has been known to reach 20-to-1 or more in the USA (Brainerd 2000). It should be noted that while other labor market institutions included widespread membership in official unions, with the exception of Poland, these unions played little role in wage determination (Brainerd 2000). Together with government policies such as relatively high minimum wages and generous maternity leave and day care benefits in most of these countries (Brainerd 2000; Kuddo 2009), this would seem to have both encouraged women to work and also to have generated relatively low (if any) gender wage gaps in these former socialist countries back in the days of socialism. Indeed, "the socialist countries of Eastern Europe and the former Soviet Union were long committed-at least nominally-to gender equality in the labor market" (Brainerd 2000: 138). For example, employer discrimination against pregnant and nursing women was prohibited, and mothers with small children had the right to work part-time-so that female labor force rates and female educational attainment in the former Soviet Union were among the highest in the world (Abdurazakova 2010). Genuine gender equality, however, was never achieved-for example, women tended to concentrate in the state subsidized sectors of the economy such as health care, medicine, education, textile, and food industries where average wages were below the overall national average, and women were substantially underrepresented in leadership and top managerial positions (Abdurazakova 2010).

But now that more than two decades have passed since the fall of the Berlin Wall, things may have changed in terms of male and female labor market outcomes-especially since some of these former socialist countries have followed very different paths. Additionally, there has since also been an international financial crisis, with possible differential effects for women and men. So, in order to put the subsequent empirical analysis in context, it would seem interesting to first examine the extent to which these formerly socialist-and previously relatively identical, at least in terms of labor market policies, especially pertaining to the relative position of women and men-countries appear similar or different in terms of labor market liberalization and gender protection, as well as the general economic developments (the latter is presented in the next sub-section).

To be sure, most former socialist countries have gone through major liberalizations-in the labor market, as well as in the economy more generally. Whereas labor markets were previously characterized by a universal and mandatory system of job security and employment stability, this has increasingly been replaced by a more liberal institutional framework in several dimensions, including hirings and firings, as well as more flexible labor relations overall (Kuddo 2009). These developments have gone on at different speeds and with legislation made at different times. On the one hand, some countries such as Slovenia (1990), Hungary and Estonia (1992), Kyrgyzstan (1994), and Albania, Croatia, and Uzbekistan (1995) adopted new labor laws early on while other countries merely amended existing laws (Kuddo 2009). Since the emergence of the new millennium, however, a second generation of labor legislation reforms has been carried out in many former socialist countries-not least due to the membership for several of these countries of the European Union, which required explicitly transforming the national labor law, leading to an overhauling of labor laws in most other former socialist countries, as well (Kuddo 2009). Among other things, this has led not only to a more flexible labor market in most countries but also to entitlements on the worker side, which may "have the potential to adversely affect labor 
market participation" (Kuddo 2009). Among the side effects here are un- and underemployment (in the formal sector), as well as an increased informal sector.

The last couple of decades have also seen explicit gender-related developments in the transition economies of the former Soviet Union, including the six economies studied here. Most notably, initially, many countries went from the formal gender equality from the Soviet times to a period with trends of re-traditionalization, which then led to the deterioration of the position of women in the economy overall. For example, women's representation in political decision-making at all levels of central and local government sharply declined following abolition of the quota system widely practiced by the countries of the former Soviet system in 1989, so that in the mid-1990s, the average proportion of women in national elected bodies was less than 8\% (Abdurazakova 2010). Additionally, the breakdown of the Eastern bloc led to an unprecedented growth and revival of religious and customary practices with impact on the status, choices, and opportunities for women, especially in rural areas (Abdurazakova 2010: 9).

Following this initial period of re-traditionalization vis-à-vis gender roles and the relative position of women in society, however, most if not all of the former transition countries of Eastern Europe and Central Asia have formally become part of several international initiatives to improve human rights, including women's rights. This includes joining the Beijing Declaration and Platform of Action and acceding to the principal international human rights instruments including the Convention on the Elimination of all Forms of Discrimination against Women (CEDAW), as well as regular government report to the Committee on the Elimination of Discrimination against Women, and active participation in subsequent review and appraisal processes (Abdurazakova 2010). Additionally, many former socialist countries, including the six examined here, have adopted stand-alone gender equality laws-in addition to confirming constitutional provisions for equality between the sexes (similar to what was declared under Soviet rule) (Abdurazakova 2010).

Relatedly, after initial abandonment of many of the programs supporting women in the labor market immediately following the breakdown of the Eastern bloc, in recent years, additional protective measures in the labor laws of many transition countries have been taken to counter low birth rates and low employment rates of females, as well as to support the status of women with small children-including maternity, parental, and paternity leaves (Kuddo 2009). The maternity leaves are particularly widespread and are also quite substantial in most transition economies, including the six studied here, where the financed durations are as follows: Kazakhstan 126 days, Tajikistan 140 days, Ukraine 126 days, Moldova 126 days, FYR Macedonia 9 months, and Serbia 365 days (Kuddo 2009: Table A10). In some countries, the duration even increases with the birth order-among the countries studied here, this is the case for Serbia, where the leave period for the third and each successive child is paid for 2 years (Kuddo 2009: Table A10). Notably, this is much more generous than most Western European countries-where in Germany, Ireland, and Portugal, for example, the duration of paid maternity leave is less than 100 days (Kuddo 2009: 52).

While paternity leaves are not that widespread and frequently of much lower duration, ${ }^{1}$ parental leaves are quite widespread among this region and frequently of substantial duration. This is also the case for two of the countries studied here, namely Moldova and Tajikistan, where the durations are until the child reaches 3 years of age and 18 months of age, respectively ${ }^{2}$; in both countries, the leave can be used by the mother, the father, or any relative who takes care of the child (Kuddo 2009: Table A10)—though when keeping in 
mind the widespread traditional mindset regarding gender roles, it seems likely that the leave will most likely be taken by the mother, thus effectively working as an enhancement of the maternity leave in these two countries.

Possibly related to these developments, female educational attainment has improved tremendously since the beginning of the economic transition across most of these countries, especially in higher education; indeed, only in Tajikistan, Uzbekistan, and Kosovo does it appear that girls are at a disadvantage relative to boys in education (Paci 2002).

In sum, progress has been made in terms of promoting gender equality and women's rights in the countries of the former Eastern bloc-including the six countries studied here. At the same time, the countries in this region remain characterized by a traditional mindset in terms of gender roles; indeed, many transition countries still have constitutional provisions that aim to protect motherhood-thus effectively working as protectionist labor legislation specifically targeted at women (Abdurazakova 2010). Additionally, "even in cases where such legislation has been abolished, discrimination against women in the labor market because of their real or potential role as wife and mother is still extremely widespread" (Abdurazakova 2010: 10). Notwithstanding the improvements in female educational attainment, females therefore still appear to be at a strong disadvantage in many of the dimensions of the former socialist countries as a whole-not least the labor market.

There therefore seem to be ample reason to explore in more detail the nature and correlates of this disadvantage specifically in terms of the female income disadvantage in transition countries, to help inform policy makers, so that these potential inequalities can be improved. Before moving on to the actual data analysis, however, recent economic trends in the six former socialist countries examined in this paper are briefly reviewed so as to "set the stage" for the subsequent empirical analysis.

\subsection{Economic trends in six former socialist economies}

While all the six countries examined in the analysis in this paper are all former socialist economies, they differ widely among themselves in terms of key economic indicators (Table 1). First, their GNI per capita (in 2008) are very different, ranging from US\$600 for Tajikistan, so that that country (along with Moldova) is below the average per capita income of even the lower-middle income countries, ${ }^{3}$ to US $\$ 6170$ for Kazakhstan, thus bringing that country well along the way towards upper-middle income status. Population growth also varies widely, ranging from Moldova, which declined at $1.4 \%$ annually over the period 2002-2008, to Kazakhstan, which grew at almost $1 \%$ annually over the same period.

Table 1 Key macro indicators for the six transition economies: 2008

\begin{tabular}{lllllll}
\hline & Kazakhstan & Macedonia & Moldova & Serbia & Tajikistan & Ukraine \\
\hline GNI per cap (US\$) & 6170 & 4130 & 1500 & 5590 & 600 & 3210 \\
Population growth (percent) & 0.9 & 0.1 & -1.4 & -0.3 & 1.3 & -0.7 \\
Labor force growth (percent) & 1.3 & 0.8 & -2.4 & NA & 4.9 & 0.1 \\
Labor force: women (percent) & 73.8 & 50.2 & 48.1 & NA & 60.5 & 62.1 \\
Labor force: men (percent) & 80.4 & 76.7 & 51.3 & NA & 77.3 & 72.4 \\
\hline
\end{tabular}

Notes: The labor force is the percentage of the female and male populations ages 15-64. Source: World Bank (2010). Growth rates are for the period 2002-2008 NA not applicable 
The growth of the labor force also differed widely across countries over the period 2002-2008, ranging from, again, a negative growth in Moldova, at 2.4\%, to almost 5\% annual growth of the labor force in Tajikistan. In terms of the gender composition of the labor force, however, these countries-except for Kazakhstan (and Serbia, where data is not available) - turn out to be quite different from Western economies by having relatively low labor force participation rates, especially for women. This probably reflects a combination of the increased non-participation and unemployment, as well as the increased importance of the informal sector in post-socialist countries (Kuddo 2009). Another noteworthy feature of the labor force participation rates of these countries is that the gender gap is quite substantial for several of these countries, again reflecting the more traditional norms and traditions in these countries as far as women and the labor market are concerned. For comparison, the labor force participation rates in the USA in 2008 were $68.3 \%$ for women and 80.1 for men-again, both substantially higher and less narrow, gender distributionwise, than several of these transition countries.

The change in the sectoral composition of the six economies (in terms of the sectoral share of GDP) in recent years roughly corresponds to the similar change in Western economies, though with some variation across countries (Table 2). In particular, the agricultural sector declined in relative terms in all six economies (with the caveat that data are not available for the first period for Serbia-and that the agricultural sector remains relatively large in Tajikistan, which therefore can be interpreted as lagging behind in the changing sectoral composition towards much less agricultural importance in the national economy witnessed in most other countries across the world, especially developed countries), whereas the service sectors mostly increase-also in line with the developments in Western economies in recent years. The evidence for industry (and manufacturing) is more mixed, especially for Moldova, where the massive decline of the agricultural sector with about two thirds leaves room for both a massive decline of the industrial sector and an impressive increase in the service sector. Given the similarities with the developments in the Western economies, it would, perhaps, therefore also not be surprising to discover the presence of a substantial gender income gap for these six countries-a finding which they would then also "share" with most (if not all) Western economies.

\section{Data and descriptive analysis}

The UNDP Social Exclusion Survey is a comprehensive nationally representative household survey aimed at evaluating living conditions and the level of social exclusion to help better plan future social and economic programs in a country. The survey was carried out for Kazakhstan, Macedonia, Moldova, Serbia, Tajikistan, and Ukraine using an identical survey instrument across all six countries of the adult population (15 years and above). The surveys

Table 2 Change in the sectoral composition of the six economies, 1998-2008 (percent of GDP)

\begin{tabular}{|c|c|c|c|c|c|c|c|c|c|c|c|c|}
\hline & \multicolumn{2}{|c|}{ Kazakhstan } & \multicolumn{2}{|c|}{ Macedonia } & \multicolumn{2}{|c|}{ Moldova } & \multicolumn{2}{|c|}{ Serbia } & \multicolumn{2}{|c|}{ Tajikistan } & \multicolumn{2}{|c|}{ Ukraine } \\
\hline & 1998 & 2008 & 1998 & 2008 & 1998 & 2008 & 1998 & 2007 & 1998 & 2008 & 1998 & 2008 \\
\hline Agriculture & 9.1 & 5.7 & 13.2 & 10.9 & 31.8 & 10.9 & NA & 13.0 & 27.2 & 18.0 & 14.2 & 8.3 \\
\hline Industry & 31.2 & 43.3 & 33.8 & 34.0 & 24.5 & 14.7 & NA & 28.4 & 27.0 & 22.9 & 36.1 & 36.9 \\
\hline lanufacturing & 12.8 & 12.7 & 20.9 & 21.7 & 17.2 & 14. & NA & NA & 20.9 & 16.5 & 29.8 & 23.3 \\
\hline Services & 59.7 & 51.0 & 52.9 & 55.1 & 43.8 & 74.5 & NA & 58.6 & 45.8 & 59.0 & 49.6 & 54.8 \\
\hline
\end{tabular}

Source: World Bank (2010)

NA not applicable 
used a multi-stage clustered and stratified sampling design involving multiple stages for each country including the region, rural-urban location, and cities/administrative division of an individual country, where the main respondent within the randomly selected household was selected either using the "next birthday" principle ${ }^{4}$ or the Kish Grid, ${ }^{5}$ both of which help ensure that the respondent is chosen randomly among all the eligible respondents in the selected household. ${ }^{6}$ Basic household information (age, gender, educational attainment) was then recorded for all household members 15 years and older-and additional information, including labor market information such as employment status, income, and job characteristics (if working).

Interviews were conducted November-December 2009. Two thousand seven hundred individuals were interviewed in each country (except for Serbia, where 300 Roma persons in the so-called Roma booster part of the survey-as of the time of this analysis-were not released as part of the main dataset, leading to an initial sample for Serbia of 2401 individuals).

Since the dependent variable is income, the sample was first conditioned on individuals who answered "yes" to having worked for payment in cash or kind for at least 1 day during the past month (7044 observations). The kind of employment which women answering "yes" to this question have, however, is likely to differ significantly across countries, so that the wage gap in one country is then potentially estimated using many more part-time or informal workers than the estimate in another country. So as to base the wage gap estimates on a similarly employed group of women (and men) in each country, the sample is therefore further restricted to full-time workers, only 6032 observations. Some workers answer "do not have any income" when asked about their own total net monthly income later in the questionnaire and therefore must be excluded, leading to an initial sample of 5971 individuals. Some individuals are either temporarily on leave from their main job and/or have missing information on income or on one or more explanatory variables and are therefore dropped from the estimation sample, as well, leading to a final total estimation sample of 5533 individuals, distributed across the six countries (and across gender) as follows: Kazakhstan 1109 (455 females, 654 males), Macedonia 928 (438 females, 490 males), Moldova 860 (508 females, 352 males), Serbia 989 (452 females, 537 males), Tajikistan 614 (245 females, 369 males), and Ukraine 1033 (496 females, 537 males). The means and standard deviations for the final estimation samples by country and gender are reported in Table 7 in Appendix 1.

The dependent variable is the individual's total net monthly income. This is potentially an issue, since in addition to labor income, the total income also includes non-labor components such as capital and rental income and public transfers, where the issue of gender discrimination studied here appears less transparent. Additionally, this measure implicitly neglects the role of taxes. ${ }^{7}$ Since the sample is restricted to individuals who worked during the past month, however, the major part of this income is plausibly labor earnings. ${ }^{8}$ One issue, however, is that the responses are reported in intervals ${ }^{9}$ (five total) - the upper and lower bounds of each of which were determined by the respective country team ${ }^{10}$-rather than the actual incomes themselves, i.e., as a continuous measure. A continuous variable was therefore created using the interval midpoints to impute actual income. ${ }^{11}$ While this is clearly less than ideal, it is a feasible way to proceed with an analysis of aggregate income data such as this-and thereby utilize this otherwise very desirable dataset. At a minimum, this clearly provides much less variation in the data than if working directly with a 
continuous income measure. ${ }^{12}$ To examine this issue a bit more-or, if nothing else, at least to bring full disclosure on this issue-Table 3 presents the original intervals and percentage of workers in each interval. From the table, the intervals appear quite different across countries; for Tajikistan, especially, the choice of the bottom income bracket appears particularly problematic, capturing more than three quarters of the entire estimation sample. Again, this is the best I can do with the available data-but is certainly a weakness of this data, which should be kept in mind when evaluating the results, as well as when providing recommendations for future research (and data collection, especially!).

The explanatory variables are specified based on standard human capital theory (Becker 1964; Mincer 1974; and, for a more recent exposition, Heckman et al. 2008) and include several potentially important individual and job characteristics, as well as geographical location-all of which have been shown to be important in previous studies of income (or earnings or wage) determinants: years of schooling, age, and age squared ${ }^{13}$ (to capture potential labor market (and other) experience), ownership/sector (created as a set of five dummy variables (public; private; mixed; cooperative, NGO, and other; and not specified $\left.{ }^{14}\right)$ ), contract status (dummy variable for no written contract/informal), social insurance coverage (dummy variable for no coverage), and geographical location (dummy for urban location). ${ }^{15}$ Lastly, it should be noted that for several of the questions used for constructing the explanatory variables used in this analysis "Don't know" and "Refuse" were given as additional categories, rather than as simply being missing per se-which is how most other surveys treat these categories. Adding a separate dummy variable of "Don't know/Refuse" for these individuals - which otherwise would be excluded-help retain these individuals in the estimation sample, and is therefore also the approach followed here.

Turning to the descriptive analysis, the average monthly incomes of females are far lower than those of males for all six countries-with the estimated gender gaps ranging from $14.4 \%$ in Serbia to $17.3 \%$ in Tajikistan, $17.6 \%$ in Macedonia, 20.6\% in Kazakhstan, 25.5\% in Moldova, and, at the top, $30.5 \%$ in Ukraine (Table 4). This supports earlier findings (Brainerd 2000; Grajek 2003; Hunt 2002; Orazem and Vodopivec 2000; and Newell and Reilly 2001) of a substantial gender earnings gap in the former socialist economies, much

Table 3 Total monthly income data: original intervals and percentage of workers in each interval

\begin{tabular}{llllllllc}
\hline Kazakhstan (tenge) & \multicolumn{5}{c}{ Moldova (leu) } \\
$\leq 20,000$ & 18.0 & 18.0 & $\leq 1000$ & 21.2 & 21.2 & $\leq 6000$ & 4.7 & 4.7 \\
$20,001-40,000$ & 41.5 & 59.5 & $1001-3000$ & 60.7 & 81.9 & $6001-12,000$ & 32.4 & 37.2 \\
$40,001-50,000$ & 22.3 & 81.8 & $3001-5000$ & 13.1 & 95.0 & $12,001-18,000$ & 28.6 & 65.7 \\
$60,001-80,000$ & 9.6 & 91.3 & $5001-10,000$ & 4.0 & 99.0 & $18,001-24,000$ & 19.3 & 85.0 \\
$>80,000$ & 8.7 & 100.0 & $>10,000$ & 1.1 & 100.0 & $>24,000$ & 15.0 & 100.0 \\
Total & $100(\mathrm{~N}=1109)$ & & $100(\mathrm{~N}=860)$ & & $100(\mathrm{~N}=928)$ \\
Serbia (dinar) & & & Tajikistan (somoni) & & Ukraine (hryvnia) & \\
$\leq 10,000$ & 2.8 & 2.8 & $\leq 600$ & 79.0 & 79.0 & $\leq 700$ & 4.9 & 4.9 \\
$10,001-20,000$ & 29.4 & 32.3 & $601-1200$ & 16.9 & 95.9 & $701-900$ & 12.2 & 17.1 \\
$20,001-40,000$ & 43.4 & 75.6 & $1201-1800$ & 2.8 & 98.7 & $901-1200$ & 21.5 & 38.6 \\
$40,001-60,000$ & 16.0 & 91.6 & $1801-2400$ & 0.8 & 99.5 & $1201-2000$ & 35.9 & 74.5 \\
$>60,000$ & 8.4 & 100.0 & $>2400$ & 0.5 & 100.0 & $>2000$ & 25.5 & 100.0 \\
Total & $100(\mathrm{~N}=989)$ & & $100(\mathrm{~N}=614)$ & & $100(\mathrm{~N}=1033)$ \\
\hline
\end{tabular}

Source: UNDP/UNICEF Social Exclusion Dataset 2010 (collected November-December 2009) 
Table 4 Raw gender income gap in six Eastern European and Central Asian countries

\begin{tabular}{lllllll}
\hline & Kazakhstan & Macedonia & Moldova & Serbia & Tajikistan & Ukraine \\
\hline Males & $10.494^{* * *}$ & $9.626^{* * *}$ & $7.445^{* * *}$ & $10.273^{* * *}$ & $6.030^{* * *}$ & $7.407^{* * *}$ \\
& {$[0.034]$} & {$[0.024]$} & {$[0.048]$} & {$[0.027]$} & {$[0.036]$} & {$[0.023]$} \\
Females & $10.288^{* * *}$ & $9.450^{* * *}$ & $7.190^{* * *}$ & $10.129^{* * *}$ & $5.858^{* * *}$ & $7.102^{* * *}$ \\
& {$[0.036]$} & {$[0.031]$} & {$[0.031]$} & {$[0.032]$} & {$[0.030]$} & {$[0.026]$} \\
Difference & $0.206^{* * *}$ & $0.176^{* * *}$ & $0.255^{* * *}$ & $0.144^{* * *}$ & $0.173^{* * *}$ & $0.305^{* * *}$ \\
& {$[0.044]$} & {$[0.037]$} & {$[0.053]$} & {$[0.035]$} & {$[0.046]$} & {$[0.032]$} \\
$N$ & 1109 & 928 & 860 & 989 & 614 & 1033 \\
\hline
\end{tabular}

Notes: Values in brackets are within-community correlation/clustering adjusted standard errors (Wooldridge 2010) (and therefore also (implicitly) robust (Huber 1967; White 1980)). Source: UNDP/UNICEF Social Exclusion Dataset 2010 (collected November-December 2009)

*Statistically significant at $10 \%$; **statistically significant at $5 \%$; ${ }^{* * *}$ statistically significant at $1 \%$

like what has been found in the Western economies. At the same time, there seems to have been a narrowing of the gap-also much like in Western economies. Staneva et al. (2010), which examines 2003 data of hourly wages for two of the countries examined here, namely Serbia and Kazakhstan (as well as Bulgaria and Russia), establishes a male-female gap of 16.1\% for Serbia and 47.8\% for Kazakhstan. Similarly, Babović (2008) finds a gender gap of $14 \%$ for monthly earnings and $17 \%$ for hourly wages using 2004 data for Serbia. Notwithstanding the difference in methodology, it nevertheless seems that the gender income gap has narrowed over the 6-7-year period between the two datasets. Again, one should keep in mind the caveats regarding the methodology regarding the collection of income information-here again especially the fact that more than three quarters of the entire estimation sample was captured in the bottom income bracket underlying the estimated income gap for the case of Tajikistan.

While the existence of substantively large gender income gaps have now been established across all six countries, the objective of the main analysis of this paper is to try to explain these gaps in terms of, on the one hand, characteristics/endowments such as educational attainment and job characteristics and returns to these characteristics (threefold division) and, on the other hand, observable and unobservable characteristics (twofold division). While the empirical strategy underlying this approach is widely used, it still seems fruitful to review the main components in some detail-which, therefore, is the objective of the next section.

\section{Estimation strategy and related issues}

The starting point of the Blinder-Oaxaca approach to decompose income (or other) differentials is an OLS regression ${ }^{16}$ of the outcome in question, estimated separately across the two relevant groups (Blinder 1973; Oaxaca 1973): here, male and female workers, respectively (suppressing subscripts for individual workers):

$$
\begin{aligned}
& Y_{\mathrm{M}}=\beta_{\mathrm{M}} X+\varepsilon_{\mathrm{M}} \\
& Y_{\mathrm{F}}=\beta_{\mathrm{F}} X+\varepsilon_{\mathrm{F}}
\end{aligned}
$$

where $Y_{\mathrm{M}}$ and $Y \mathrm{~F}$ are the logarithms of monthly income of male and female workers respectively, $X$ is a vector of workers' characteristics (education, experience, and so on), $\beta_{\mathrm{M}}$ and $\beta_{\mathrm{F}}$ are the returns to the workers' characteristics, and $\varepsilon_{\mathrm{M}}$ and $\varepsilon_{\mathrm{F}}$ are error terms. 
As such, these regressions are-at least in this context-merely inputs into calculating the decompositions. However, it is potentially fruitful to consider these auxiliary regressions in and of themselves as separate and integral parts of the overall analysis, also, not only because the results from these regressions directly indicate the different returns to characteristics across gender but also because their specification, most notably in terms of explanatory variables, will affect the subsequent decomposition results.

Human capital theory suggests that education and potential experience directly affect income through the impact on individuals' productivity in the labor market and also suggest additional factors that are potentially important determinants of income. Hence, the first part of the multivariate analysis will examine these relationships, using ordinary least squares. Due to the nature of the data, I will also estimate the Mincer regressions using interval regressions (this is basically a generalization of the tobit model, since it extends censoring beyond left-censored data or right-censored data-see Cameron and Trivedi (2010, 548-550) and Wooldridge (2016, sec. 17.4) for more details).

Further, if additionally estimating Mincer regressions using quantile regressions instead of OLS (or interval regression)-following, for example, the approach laid out in Albrecht et al. (2003) - it is possible to test for the presence of a glass ceiling related to gender. ${ }^{17}$ I will do that as part of the analysis here, as well. Additionally, while it is debatable whether variables such as industry and occupation which themselves reflect the impact of discrimination should be included as controls, I will examine the importance of adding industry and occupation to the Mincer regressions in a sensitivity analysis.

One potentially important econometric issue here is that educational attainment may be endogenous. The main concern here is possible omitted variables bias. Preferences and ability, for example, are unobserved and at the same time also, at least to some extent, determine both educational attainment and labor market income. However, as there are not available in this dataset any variables that may potentially act as instruments, it does not appear feasible to try to address this problem using instrumental variable methods. The effect of any omitted variables will therefore be captured by the error term, possibly causing omitted variables bias. As a result, any subsequent results must be interpreted with caution and hence not given a causal interpretation but rather as merely reflecting associations with labor market income.

Relatedly, there is the possibility that selection could be partly driving any observed gender gap. An apparently small gender income gap, for example, could be due to less qualified female workers withdrawing from the labor market to a greater extent than more qualified female workers. In that case, it would then appear as if the gender income gap is relatively small-and, thus, also that there is not strong evidence for any gender-based income discrimination being present-when in fact, this is all driven by unobservables. Due to the nature of the data-including it being a multipurpose household survey (though focused on social exclusion) rather than specifically a labor force survey-it is not possible to delve more into this issue, unfortunately. As a result, the subsequent results again must be interpreted with caution, keeping in mind this caveat.

Again, these income regressions formally are merely inputs into the decomposition analysis. Specifically, the decomposition analysis amounts to examining to which extent the observed income gaps across gender are attributable to differences in the observable characteristics, to differences in the returns to those characteristics, and to the interaction of the two ("threefold decomposition," see below for details) and, relatedly, to which extent 
the observed income gaps are due to observable and unobservable characteristics ("twofold decomposition," see below for details). This analysis will comprise the second part of the multivariate empirical analysis and will be pursued as an Oaxaca-Blinder-type decomposition.

Formally, following the methodology of Oaxaca (1973) and Blinder (1973), the difference in mean incomes for male and female sector workers, denoted $R$, can be decomposed into three parts (Jann 2008) using the empirical counterparts of Eqs. (1) and (2) above ${ }^{18}$

$$
R=\bar{Y}_{\mathrm{M}}-\bar{Y}_{\mathrm{F}}=\left(\bar{X}_{\mathrm{M}}-\bar{X}_{\mathrm{F}}\right) \hat{\beta}_{\mathrm{M}}+\bar{X}_{\mathrm{M}}\left(\hat{\beta}_{\mathrm{M}}-\hat{\beta}_{\mathrm{F}}\right)-\left(\bar{X}_{\mathrm{M}}-\bar{X}_{\mathrm{F}}\right)\left(\hat{\beta}_{\mathrm{M}}-\hat{\beta}_{\mathrm{F}}\right)
$$

This is a threefold decomposition (Winsborough and Dickinson 1971), where the first term represents the "endowments effect" and explains the differences that are due to worker characteristics (such as education and sector of employment). The second term reflects the "coefficients effect," which shows the differences in the estimated returns to male and female sector workers' characteristics. Lastly, the third term, the "interaction effect," accounts for the fact that differences in endowments and coefficients between male and female workers exist simultaneously. If male and female workers obtain equal returns for their characteristics, the second and the third part in Eq. (3) will equal to zero and income differentials between male and female workers will be explained by the differences in endowments alone.

The above decomposition is formulated based on the prevailing income structure of male sector workers, i.e., the differences in endowments and coefficients between male and female workers are weighted by the coefficients (returns) of male sector workers. This seems reasonable for the application here, since males dominate in the labor force, at least in an economic sense/size-wise-as also revealed by the existence of substantial "raw" income gaps presented in Table 3. This is therefore also the approach pursued in the subsequent analysis. ${ }^{19}$

An alternative approach, prominent in the literature on wage discrimination, is based on the assumption that wage differentials are explained by a unifying "non-discriminatory" coefficient vector, denoted $\beta^{*}$, which is estimated in a regression that pools together both of the two groups under consideration (here, male and female workers). Then, the income gap can be expressed as

$$
R=\bar{Y}_{\mathrm{M}}-\bar{Y}_{\mathrm{F}}=\left(\bar{X}_{\mathrm{M}}-\bar{X}_{\mathrm{F}}\right) \hat{\beta} *+\bar{X}_{\mathrm{M}}\left(\hat{\beta}_{\mathrm{M}}-\hat{\beta} *\right)+\bar{X}_{\mathrm{F}}\left(\hat{\beta} *-\hat{\beta}_{\mathrm{F}}\right)
$$

The above equation represents the so-called twofold ${ }^{20}$ decomposition:

$$
R=Q+U
$$

where $Q=\left(\bar{X}_{\mathrm{M}}-\bar{X}_{\mathrm{F}}\right) \hat{\beta}^{*}$ is the part of the income differential that is "explained" by sample differences assessed with common "returns" across the two groups and the second term $U$ $=\bar{X}_{\mathrm{M}}\left(\hat{\beta}_{\mathrm{M}}-\hat{\beta}^{*}\right)+\bar{X}_{\mathrm{F}}\left(\hat{\beta}^{*}-\hat{\beta}_{\mathrm{F}}\right)$ is the "unexplained" part not attributed to observed differences in male and female characteristics. The latter part is often treated as discrimination in the literatures on gender and racial income gaps. It is important to note, however, that the "unexplained" part also captures all potential effects of differences in unobserved variables (Jann 2008). And, to be sure, in the application here, it is indeed possible to talk about "discrimination," per se, as being a female worker is an intrinsic characteristic. Again choosing the male income structure as the reference, (4) reduces to 


$$
R=\bar{Y}_{\mathrm{M}}-\bar{Y}_{\mathrm{F}}=\left(\bar{X}_{\mathrm{M}}-\bar{X}_{\mathrm{F}}\right) \hat{\beta}_{\mathrm{M}}+\bar{X}_{\mathrm{F}}\left(\hat{\beta}_{\mathrm{M}}-\hat{\beta}_{\mathrm{F}}\right)
$$

Again, while the main analysis here takes the male income structure as the reference, several different specifications for the baseline specification (also known as the "absence of discrimination" specification), i.e., $\hat{\beta}^{*}$ in (4), will be pursued in the sensitivity analysis as a robustness check.

The standard errors of the individual components in Eqs. (3) and (4) above are computed using the Delta method by applying the procedure detailed in Jann (2008), which extends the earlier method developed in Oaxaca and Ransom (1998) to deal with stochastic regressors.

In addition to examining the overall composition of the established income gaps, it would seem instructive to perform detailed decompositions, as well, whereby it is possible to see which explanatory variables contribute the most to the three- and/or twofold overall decompositions. Similar to the OLS regressions, the detailed decomposition estimations also all allow for arbitrary heteroskedasticity (Huber 1967; White 1980). So as to condense the wealth of results obtained here-thereby easing the interpretation of the many results-the detailed decompositions are done group-wise, rather than for each individual variable (for example, for sector as a whole, rather than separately for public, private, and so on). Here, too, the focus will be on the case where the male structure is taken as the reference, though the sensitivity analysis again will consider alternative specifications, as well.

\section{Results}

This section reviews the main results. This is done in three main parts: (i) Mincer income regressions, (ii) overall income decompositions, and (iii) detailed income decompositions. It should be noted that since some of the tables are rather large, they have been placed in the appendices (but are referred to, and discussed, in the body text below).

\subsection{Mincer income regressions}

Starting with the results that are most consistent across all six countries, in line with previous research, the results from the Mincer regressions reveal substantial returns to education (Table 8 in Appendix 2). Frequently, the return to an additional year of schooling is larger for females than for males. For Serbia, for example, the return to an additional year of education is $8 \%$ for females but only $5.5 \%$ for males-which is consistent with previous evidence (Blunch and Sulla 2010; Staneva et al. 2010). ${ }^{21}$ The evidence on returns to ownership is mixed across countries, though frequently there is not much of an association. For Kazakhstan and Serbia, for example, there is no statistical difference across ownership status. Having no written contract (reference: written contract) is associated with an income penalty, though not always statistically significantly so. The "Don't know"/"Refuse" category again experiences a negative return in several cases-and both substantively and statistically significantly so for the cases of Serbian and Moldovan males. Not being covered by social security on the main job (reference category: covered) is associated with a negative and frequently substantively large income premium in several cases-and for Serbia for both females and males, both also statistically significant. Workers from urban areas tend to receive a positive income premium, which again accords well with their living expenses being larger, also. 
Is there a glass ceiling related to gender in one or more of these former socialist economies? This is a testable hypothesis and I examine this using the approach laid out in $\mathrm{Al}$ brecht et al. (2003) for the case of Sweden, by estimating quantile regressions for the pooled (by gender) Mincer regressions-with clustered standard errors, following Parente and Santos Silva (2016). From these results, there is some evidence of a glass ceiling for Moldova and Ukraine, where the gender gaps are stronger at the higher end of the income distribution, whereas the evidence for the other countries is more mixed (Table 11 in Appendix 3).

\subsection{Sensitivity analysis}

There are potential issues with the previous analysis, and so it would be prudent to examine these issues in a set of sensitivity analyses. First, estimating the Mincer regressions (which, again, feed into the subsequent decomposition analysis) by OLS, using the interval midpoints, disregards the inherent interval nature of the underlying data. To explicitly incorporate the interval nature of the underlying data-and therefore also implicitly examine the consequences of the simplifying assumptions underlying the OLS estimations, using the interval midpoints-I instead estimate the Mincer equations using interval regression using the full interval data (this is basically a generalization of the tobit model, since it extends censoring beyond left-censored data or right-censored data-see Cameron and Trivedi (2010, 548-550) and Wooldridge (2016, sec. 17.4) for more details) (Table 5 and Table 9 in Appendix 2).

From Table 5, the results for the raw gender gaps are virtually identical to the OLS results, except for Tajikistan. Further estimating the full Mincer regressions using interval regression (Table 9 in Appendix 2), while there are some differences, the results are fairly robust, overall. With such relatively minor differences between the OLS and interval regression results, it seems prudent to continue with OLS for the remainder of the analysis.

The Mincer regressions estimated so far are purposely sparse in terms of the amount of explanatory variables. This is both to keep the analysis simple and because the inclusion of certain explanatory variables is debatable. In particular, some explanatory variables may themselves reflect the impact of discrimination, whereby their inclusion leads to understating the "unexplained gender wage/income gap" (the presence of which is taken by many researchers to measure the amount of discrimination, though it is really only consistent with the presence of discrimination) (Altonji and Blank 1999: 3191). Hence, one view here is that such variables may better be left out when estimating Mincer regressions, especially when the focus is on possible (gender, racial or other) discrimination. This is the case especially

Table 5 Estimated gender coefficients from gender dummy, only. Estimations: OLS and interval regression

\begin{tabular}{lllllll}
\hline & Kazakhstan & Macedonia & Moldova & Serbia & Tajikistan & Ukraine \\
\hline OLS (using mid-points) & $-0.206^{* * *}$ & $-0.176^{* * *}$ & $-0.255^{* * *}$ & $-0.144^{* * *}$ & $-0.173^{* * *}$ & $-0.305^{* * *}$ \\
& {$[0.046]$} & {$[0.038]$} & {$[0.054]$} & {$[0.034]$} & {$[0.047]$} & {$[0.031]$} \\
Interval regression & $-0.208^{* * *}$ & $-0.171^{* * *}$ & $-0.251^{* * *}$ & $-0.150^{* * *}$ & $-0.369^{* * *}$ & $-0.308^{* * *}$ \\
& {$[0.043]$} & {$[0.038]$} & {$[0.054]$} & {$[0.035]$} & {$[0.113]$} & {$[0.030]$} \\
$N$ & 1109 & 928 & 860 & 989 & 614 & 1033 \\
\hline
\end{tabular}

Notes: Values in brackets are within-community correlation/clustering adjusted standard errors (Wooldridge 2010) (and therefore also (implicitly) robust (Huber 1967; White 1980)). Source: UNDP/UNICEF Social Exclusion Dataset 2010 (collected November-December 2009)

*Statistically significant at $10 \%$; **statistically significant at $5 \%$; ${ }^{* * *}$ statistically significant at $1 \%$ 
for industry and occupation, which is why (in addition to the inclusion of these variables leading to quite thin cells for many of these groups) I have left these variables out of the analysis, so far. On the other hand, it would still seem useful to at least explore the consequences of adding industry and occupation as a robustness check-as well as to potentially gain insights into possible gender-based sorting into occupations and/or industry, so that including these may provide additional information on segregation.

From the results from these augmented Mincer (OLS) regressions, it can be seen that the estimated coefficients are indeed frequently statistically insignificant due to the frequently quite small cell sizes (Table 10 in Appendix 2). Additionally, however, the results also reveal that men receive an income premium in traditional male-dominated industries such as mining, manufacturing, and construction-whereas there does not seem to be any such patterns for women. For occupation, the dummies are largely statistically insignificant. These results thus provides some, though arguably limited, evidence on selection and sorting into industry-if not occupation-in these countries. Given the small cell sizes and therefore frequently statistically insignificant results, it again seems prudent to continue with the more parsimonious specification estimated previously for the remainder of this analysis.

\subsection{Overall income decompositions}

A couple of results stand out particularly strongly from the results of the threefold decompositions (Table 6, top panel). First, the endowments decrease the female income gap overall in several cases (although not always statistically significantly so), indicating that women have relatively more favorable observable characteristics-that is, they are concentrated in better paying sectors, have more education, and so on (this will be examined more closely when considering the detailed decompositions in the next sub-section). Second, the returns to characteristics increase the gaps in both substantive and statistical terms, and for all

Table 6 Overall income decompositions: three- and twofold

\begin{tabular}{|c|c|c|c|c|c|c|}
\hline & Kazakhstan & Macedonia & Moldova & Serbia & Tajikistan & Ukraine \\
\hline \multicolumn{7}{|l|}{ Threefold } \\
\hline \multirow[t]{2}{*}{ Endowments } & $-0.062^{* *}$ & -0.03 & 0.038 & $-0.070^{* * *}$ & 0.008 & -0.006 \\
\hline & {$[0.026]$} & {$[0.023]$} & {$[0.026]$} & {$[0.023]$} & {$[0.021]$} & {$[0.018]$} \\
\hline \multirow[t]{2}{*}{ Coefficients } & $0.293^{* * *}$ & $0.208^{* * *}$ & $0.201^{* * *}$ & $0.191^{* * *}$ & $0.141^{* * *}$ & $0.310^{* * *}$ \\
\hline & {$[0.041]$} & {$[0.033]$} & {$[0.053]$} & {$[0.031]$} & {$[0.045]$} & {$[0.032]$} \\
\hline \multirow[t]{2}{*}{ Interaction } & -0.025 & -0.003 & 0.016 & 0.023 & 0.024 & 0.001 \\
\hline & {$[0.023]$} & {$[0.018]$} & {$[0.028]$} & {$[0.015]$} & {$[0.026]$} & {$[0.018]$} \\
\hline \multicolumn{7}{|l|}{ Twofold } \\
\hline \multirow[t]{2}{*}{ Explained } & $-0.087^{* * *}$ & $-0.032^{*}$ & $0.054^{*}$ & $-0.047^{* *}$ & 0.032 & -0.005 \\
\hline & {$[0.028]$} & {$[0.019]$} & {$[0.032]$} & {$[0.020]$} & {$[0.020]$} & {$[0.013]$} \\
\hline \multirow[t]{2}{*}{ Unexplained } & $0.293^{* * *}$ & $0.208^{* * *}$ & $0.201^{* * *}$ & $0.191^{* * *}$ & $0.141^{* * *}$ & $0.310^{* * *}$ \\
\hline & {$[0.041]$} & {$[0.033]$} & {$[0.053]$} & [0.031] & {$[0.045]$} & {$[0.032]$} \\
\hline N & 1109 & 928 & 860 & 989 & 614 & 1033 \\
\hline \multicolumn{7}{|c|}{$\begin{array}{l}\text { Notes: Decompositions are from females' viewpoint, i.e., using male endowments and returns (sensitivity analysis using } \\
\text { reverse decompositions for the threefold decomposition and several alternative weights given to males relative to } \\
\text { females/regression model used in determining the reference coefficients for the twofold decompositions are reported in } \\
\text { Appendices } 4 \text { and 5, respectively). Values in brackets are within-community correlation/clustering adjusted standard } \\
\text { errors (Wooldridge 2010) (and therefore also (implicitly) robust (Huber 1967; White 1980)). Source: UNDP/UNICEF Social } \\
\text { Exclusion Dataset } 2010 \text { (collected November-December 2009) }\end{array}$} \\
\hline
\end{tabular}


countries, indicating that males have higher returns to characteristics overall. Notably, this result is much more consistent than the result regarding endowments-with the estimated effects ranging from a minimum of $14.1 \%$ (for Tajikistan) to as much as $31 \%$ (for Ukraine). It should be noted that the low coefficient effect in Tajikistan should probably not be attributed to improving conditions in that country- but probably rather to the fact that (as also discussed previously in Section 3) the bottom income bracket in that country was chosen extremely large by the questionnaire designers, which will then lead to less income inequality overall and therefore likely also to a smaller male-female income gap.

Moving to the twofold decompositions, females on average have better employmentrelated characteristics (such as educational attainment and sector of employment) as indicated by the negative sign in the explained part-which in turn serves to narrow the overall income gap-whereas the unexplained part (capturing all the factors that cannot be attributed to differences in observed worker characteristics) accounts for an even larger share of the gender income differential (Table 6, bottom panel).

Notably_as can be seen from the results from the sensitivity analysis shown in Appendices 4 and 5 (Tables 12 and 13 respectively) - these results are quite robust to whether the decomposition is performed from females' viewpoint (i.e., using male endowments and returns) or whether the decomposition is performed from males' viewpoint (i.e., using female endowments and returns) for the threefold decompositions or from any of the many different possibilities of specifying the "absence of discrimination" group in the twofold decompositions.

Overall, these results are consistent with earlier findings for the region (Newell and Reilly 2001; Reva 2010; Babović 2008; Staneva et al., 2010) —and, thus, are indicative of substantial income discrimination against females in the labor markets of all six countries. But how are the overall gaps-both two- and threefold-explained by the endowment of and returns to the separate individual characteristics (or groups of characteristics), rather than by the endowment of and returns to individual characteristics overall? This is the object of the final empirical analysis, following next.

\subsection{Detailed income decompositions}

The detailed income decompositions allow further decomposing the overall gaps just established into the individual explanatory variables from the Mincer income regressions, discussed earlier. To help better facilitate interpretation, however, results are reported in groups of individual variables (e.g., aggregating up the contribution from all the ownership variables).

The results from the detailed threefold decompositions (Tables 14-19 in Appendix 6) reveal that in several cases, one of the most important contributors to the narrowing of the gender income gap-both substantively and statistically-in terms of individual characteristics, is education. For both Kazakhstan and Serbia, for example, education accounts for almost all of the explained gap-and at about 3\%-points, education also accounts for a substantial part of the Ukrainian income gap. For Macedonia, although substantively large (at $2.2 \%$-points), the effect is not statistically significant. For Moldova and Tajikistan, however, the effect is practically nil-both in substantive and statistical terms. In several cases, education also works to improve the gender gaps through the part attributable to characteristics, again consistent with earlier studies (Babović 2008; Blunch and Sulla 2010; Staneva et al. 2010). ${ }^{22}$ Other observable characteristics and returns widen the gender gap, however. For 
Serbia and Moldova, for example, the returns to contract status widen the gap, as do social security in Ukraine. With a few exceptions, most of the remaining estimated effects are not statistically significant.

The results from the detailed twofold decompositions are mostly consistent with the results for the detailed threefold decompositions (Tables 20-25 in Appendix 7), so that education again is the most consistently important contributor to narrowing the gender income gap across all six countries, except for Moldova and Tajikistan, where the effect again is practically nil-both in substantive and statistical terms.

\section{Conclusions}

This paper examines the gender income gap in terms of its prevalence, magnitude, and determinants using a recent data set collected using identical survey instruments for six countries from Eastern Europe and Central Asia and thereby adds to the emerging, somewhat fragmented (partly because of using many different, not always comparable data sources) literature on the gender income gap for the former socialist economies.

Using a range of estimators, including OLS, interval regression, quantile regression, and overall and detailed income decompositions, four main results are established: (1) the presence of a substantively large gender income gap (favoring males) in all six countries; (2) some evidence of a gender-related glass ceiling in some of these countries; (3) some evidence that endowments diminish the income gaps, while the returns to characteristics increase the gaps-indicating that in some countries, women are concentrated in better paying sectors, have more education, and so on, while males have higher returns to characteristics overall; and (4) while observed individual characteristics explain a part of the gaps, a substantial part of the income gap is left unexplained.

These results have strong policy implications, consistent as they are with the presence of income discrimination towards females in the labor market. In particular, the continued presence of a gender income gap is likely to keep out females from the labor force that would otherwise be active participants and add to the economy. While increased economic activity has been important during the transition from a planned to a market economy, with the recent financial crisis, such efforts are perhaps more important than ever-thus highlighting not only the importance of both employment generation but also the improvements of the regulatory environment, since the former may be severely dampened with the continued presence of a substantively larger gender income gap.

But what are some of the potential mechanisms driving the gender income gap observed here-and does economic policy have a possible role to play? It was noted in the review of these countries' historical and economic background how, after initially abandoning programs specifically supporting the role of women in the labor market, most countries have gone back to instituting such programs anew.

Among such programs are paid maternity leave, where many countries have programs providing extensive programs-frequently of a duration longer even than in many advanced Western economies. As has also been noted elsewhere (Kuddo 2009: 78-79), these extensive programs may adversely affect women's labor market participation, as well as lead to actual or perceived erosion of skills, and, perhaps even more importantly, act to create reluctance on the part of employers to hire women of childbearing age, to avoid the associated indirect costs such as replacement workers. And the longer the leave, the greater the perceived disincentive from the employers' point of view. As also noted earlier, the parental leaves prevalent 
in some transition countries-since they frequently can be expected to be taken by the mother-may effectively act as an additional maternity leave. To counter this cycle, therefore, one possibility is to bring the leave durations more in line with those in Western economies-though, as also suggested by Kuddo (2009: 78), so as to continually help support women's access to the labor market, this should be combined with better access to child care facilities. Alternatively, extension of paternal leaves may be an option. In many transition countries, these are either absent or of an extremely short duration, sometimes only 1 week (Kuddo 2009: Table A10). Introducing (or extending) paternal leaves of a much longer duration would help level the playing field for men and women more in the labor market, since employers now would have to expect a potential leave of any employee of childbearing age (or for the males, with a wife of childbearing age), regardless of gender. As a possible side effect, such institutionalized gender equality in terms of child-birth related leaves may also help bring about more tolerance and openness to childbearing as a reason for detaching from the labor market for a shorter or longer period, regardless of the gender of the worker.

In terms of future research, even with the evidence emerging in recent years, we are only beginning to start to get a grasp of the prevalence and the nature of the gender income gap in the former socialist economies in Eastern Europe and Central Asia. Even more research is needed, especially if we want to go into the "black box" of what determines the gender income gap in terms of causal pathways. Crucial for these efforts, however, is the availability-and therefore collection-of more and better data.

The data examined here is a case in point. While it is certainly commendable-and very useful - to collect data using identical questionnaires for several countries simultaneously, it is a shame that such an important variable as labor income (income) is reported (if not collected) in such a way that the variation and therefore the informational content of this key variable is heavily diminished. An additional limitation of this dataset was the somewhat small survey sample sizes (certainly if conditioning on currently working adults), among other things limiting the amount of explanatory variables to relatively few individual and job characteristics, so as to avoid too small cell sizes. In turn, these comments may well serve as a warning to national and international agencies in charge of future data collection.

\section{Endnotes}

${ }^{1}$ Among the six countries studied here, only Macedonia has paternity leave-and with a duration of only up to 7 days (Kuddo 2009: Table A10).

${ }^{2}$ In Tajikistan, there is a possibility for an additional unpaid leave until the child reached 3 years of age.

${ }^{3}$ Which was US\$2078 in 2008 (World Bank 2010).

${ }^{4}$ Which refers to choosing, among all the eligible respondents (here, individuals 15 years and above), in a given chosen household the person with the next birthday as the respondent of the household.

${ }^{5}$ See Kish (1949) for details.

${ }^{6}$ See TNS (2010) for more details.

${ }^{7}$ Different countries may have different taxation methods, but there is unfortunately not much to do about this in practice, apart from providing a cautionary remark.

${ }^{8}$ Some might prefer instead to examine wage rates, but unfortunately, hours worked are not available in the current dataset. It may be argued, however, that if one is interested in 
total worker welfare per se, one should indeed be examining total labor earnings (a proxy of which is available here) rather than the wage rate.

${ }^{9}$ The questionnaire refers to them as "local currency (20 quintile) UNDP intervals," "local currency (40 quintile) UNDP intervals," etc., but they are not quintiles in the usual meaning of the word since they do not each contain 20 of the sample (neither among the total sample or the subsample that was working within the past month).

${ }^{10}$ Based on personal correspondence with Susanne Milcher, Social Inclusion and Poverty Reduction Specialist, UNDP

${ }^{11}$ Specifically, if belonging in the four lowest income brackets (see Table 3 below), I assume that peoples' income is the midpoint of the respective income bracket, and if belonging in the top bracket, I assume that peoples' income is the sum of the upper class point of the bottom bracket and the lower class point of the top bracket. The latter seems to help provide a conservative estimate of the degree of overall earnings inequality and therefore, to the extent that females probably are underrepresented in the top earnings bracket, also a conservative estimate of the female-male earnings gap.

${ }^{12}$ Additionally, however, I also conduct a sensitivity analysis where I instead estimate interval regressions to examine the robustness of the OLS results using the interval mid-points.

${ }^{13}$ Divided by 100 , for scale consistency with the other explanatory variables

${ }^{14}$ "Not specified" was specified as a separate category in the questionnaire and is therefore also treated as a separate group here.

${ }^{15}$ The dataset also includes information on occupation (14 categories) and industry (18 categories), but inclusion of these as explanatory variables is debatable since if they themselves reflect the impact of discrimination, they will understate the "unexplained gender wage/income gap" (the presence of which is taken by many researchers to measure the amount of discrimination, though it is really only consistent with the presence of discrimination) (Altonji and Blank 1999: 3191). Additionally, including these variables frequently leads to some very small cell sizes and therefore also very imprecisely measured results for these variables; these variables are therefore not included in the main analysis (I do, however, include them in a sensitivity analysis).

${ }^{16}$ With within-community correlation/clustering adjusted standard errors incorporated (Wooldridge 2010) (and therefore also (implicitly) robust (Huber 1967; White 1980)).

${ }^{17}$ I also allow for clustered standard errors in the quantile regressions, following Parente and Santos Silva (2016).

${ }^{18}$ In the following, bars on top of variables denote mean values, while $\hat{\beta}$ denotes estimated coefficient values from Eqs. (1) and (2) above.

${ }^{19}$ Alternatively, however, this equation could also be represented based on the prevailing earnings structure of female workers; this will be explored further in the sensitivity analysis.

${ }^{20}$ See Oaxaca (1973), Blinder (1973), Cotton (1988), Reimers (1983), Neumark (1988), and Jann (2008) for different approaches-basically, these differ in the relative weights they attribute to the two groups in the decomposition.

${ }^{21}$ In contrast, somewhat surprisingly, Reva 2010 finds that male returns are higher than female returns for all levels of education in Serbia.

${ }^{22}$ Again, detailed gender earnings decomposition are only available for very few countries in the region. 


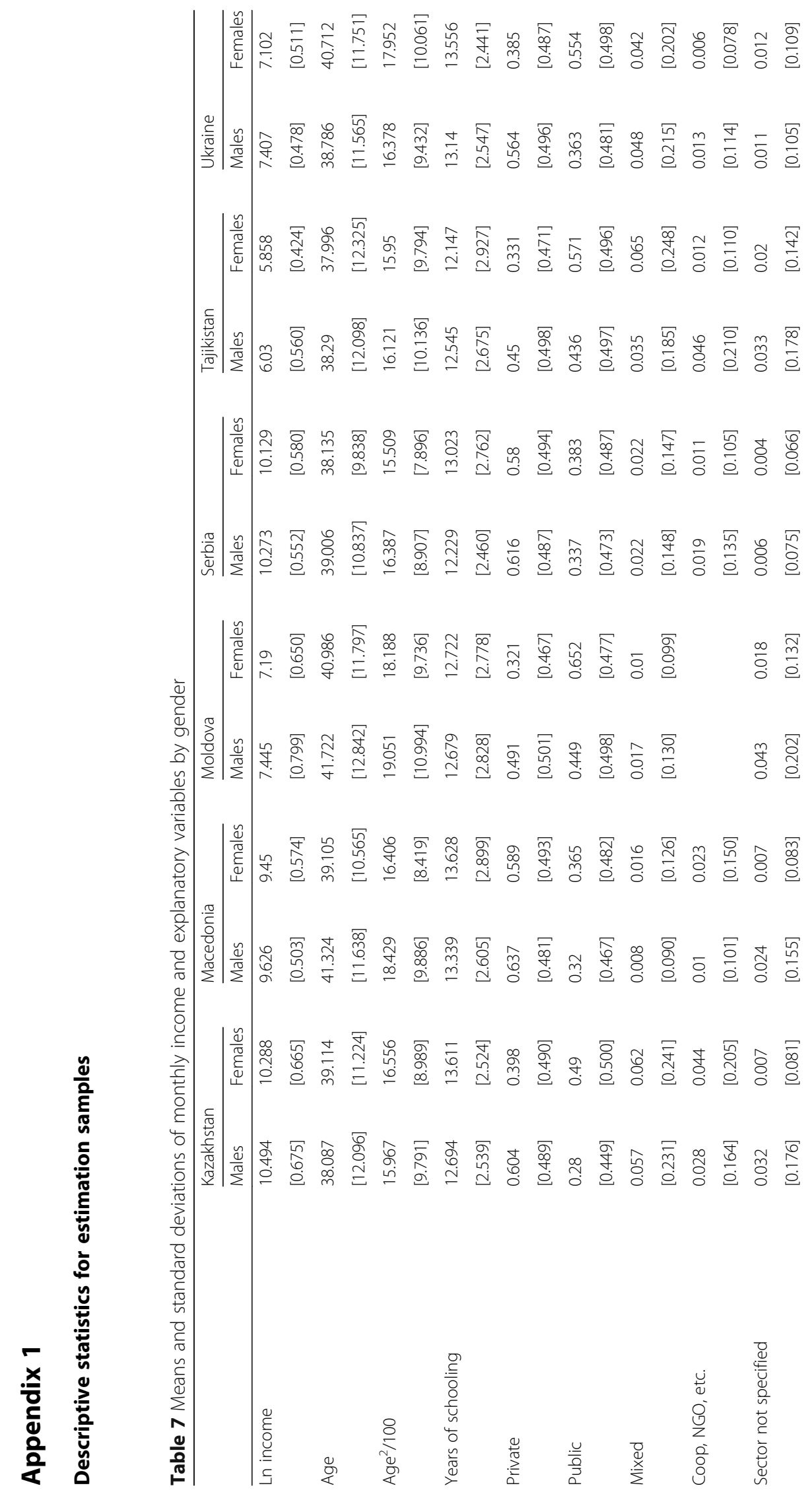




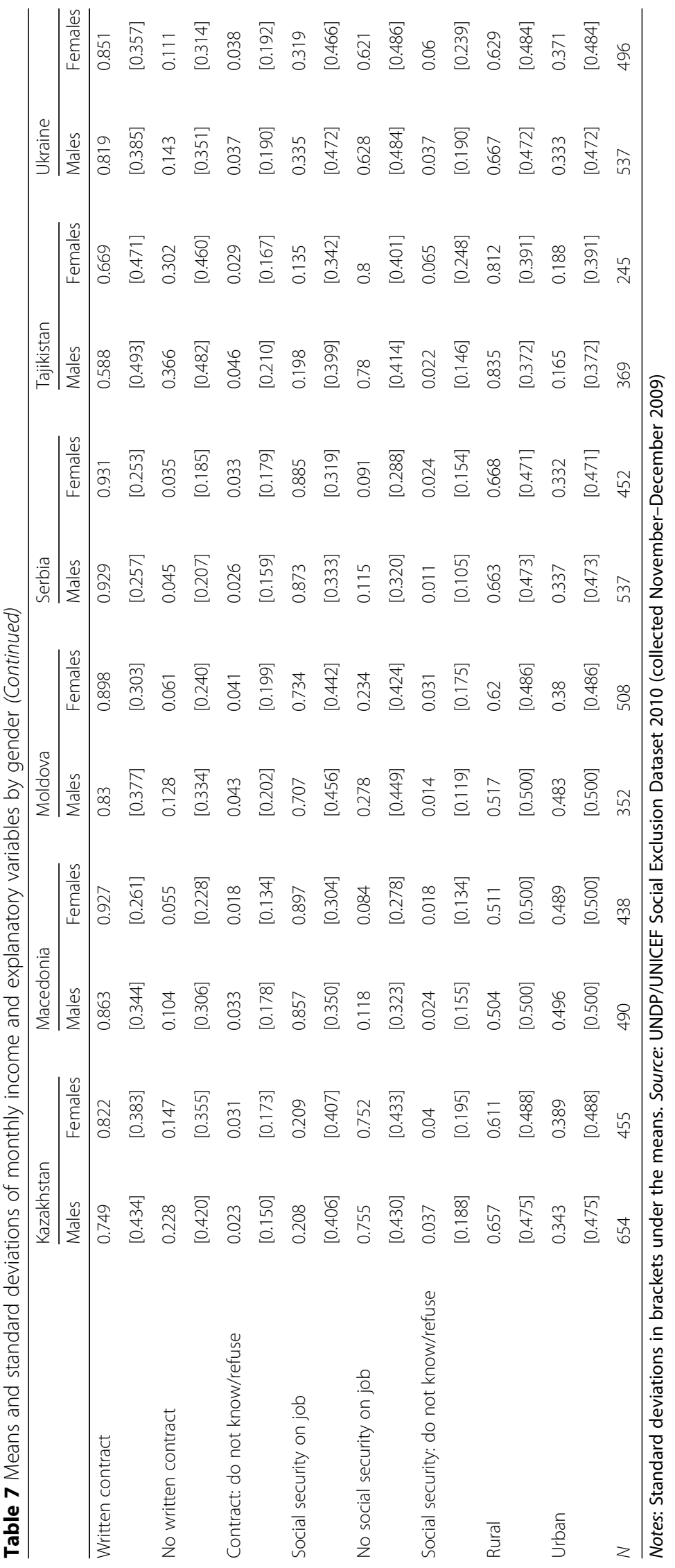




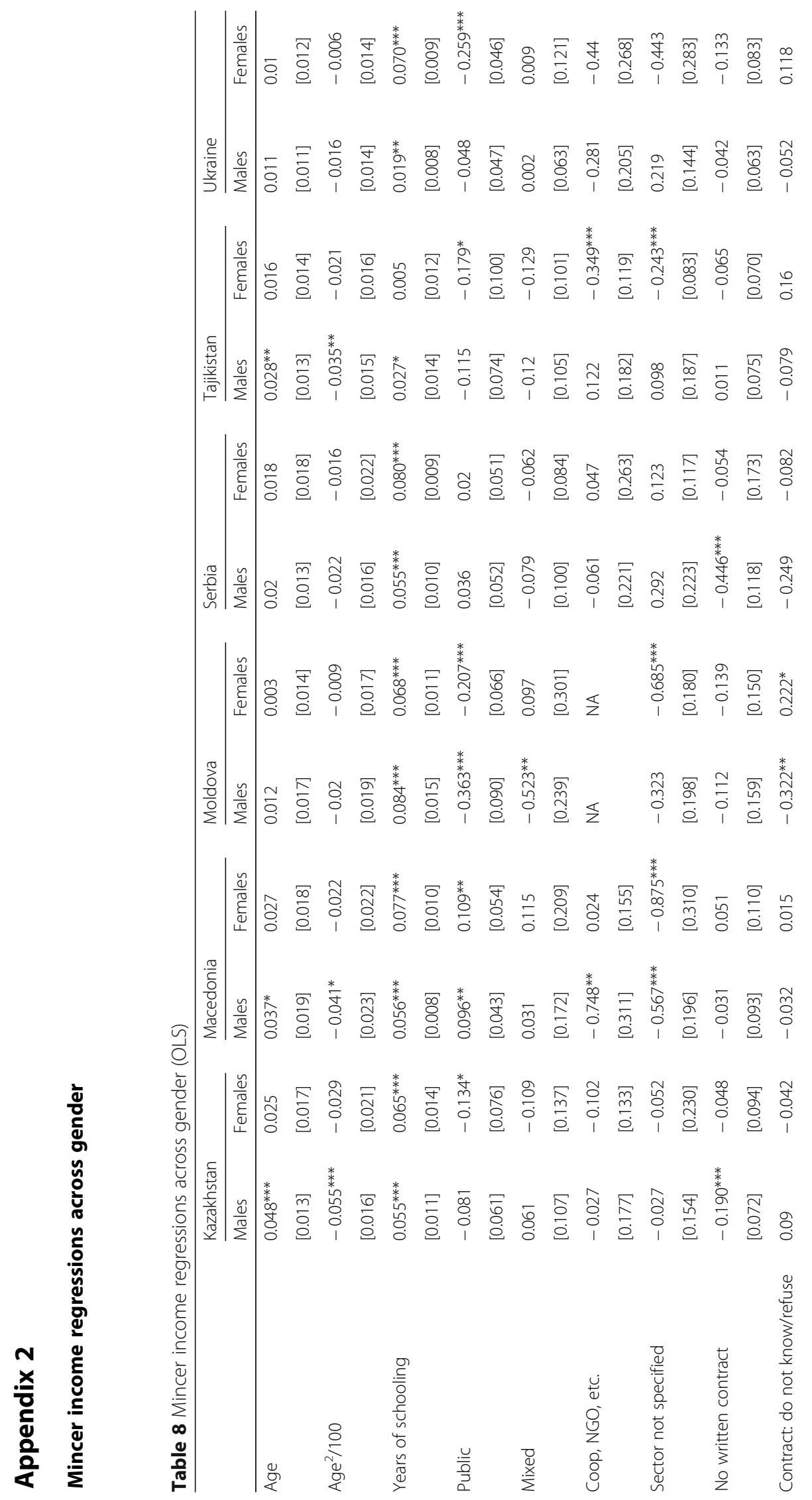




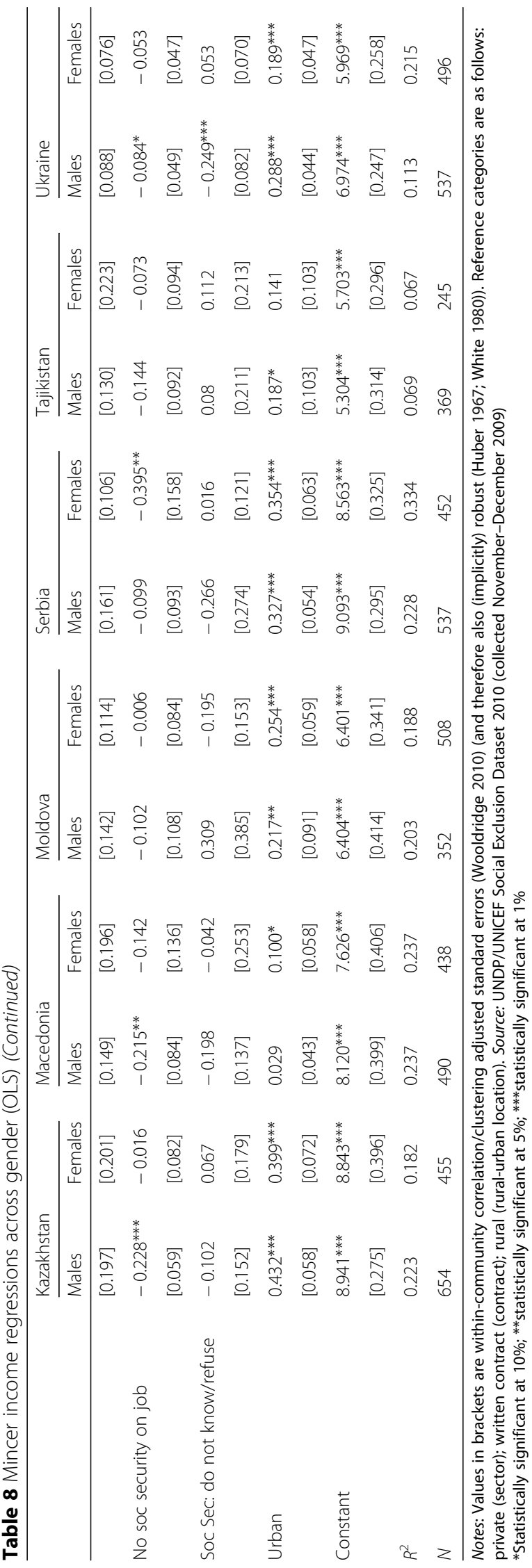




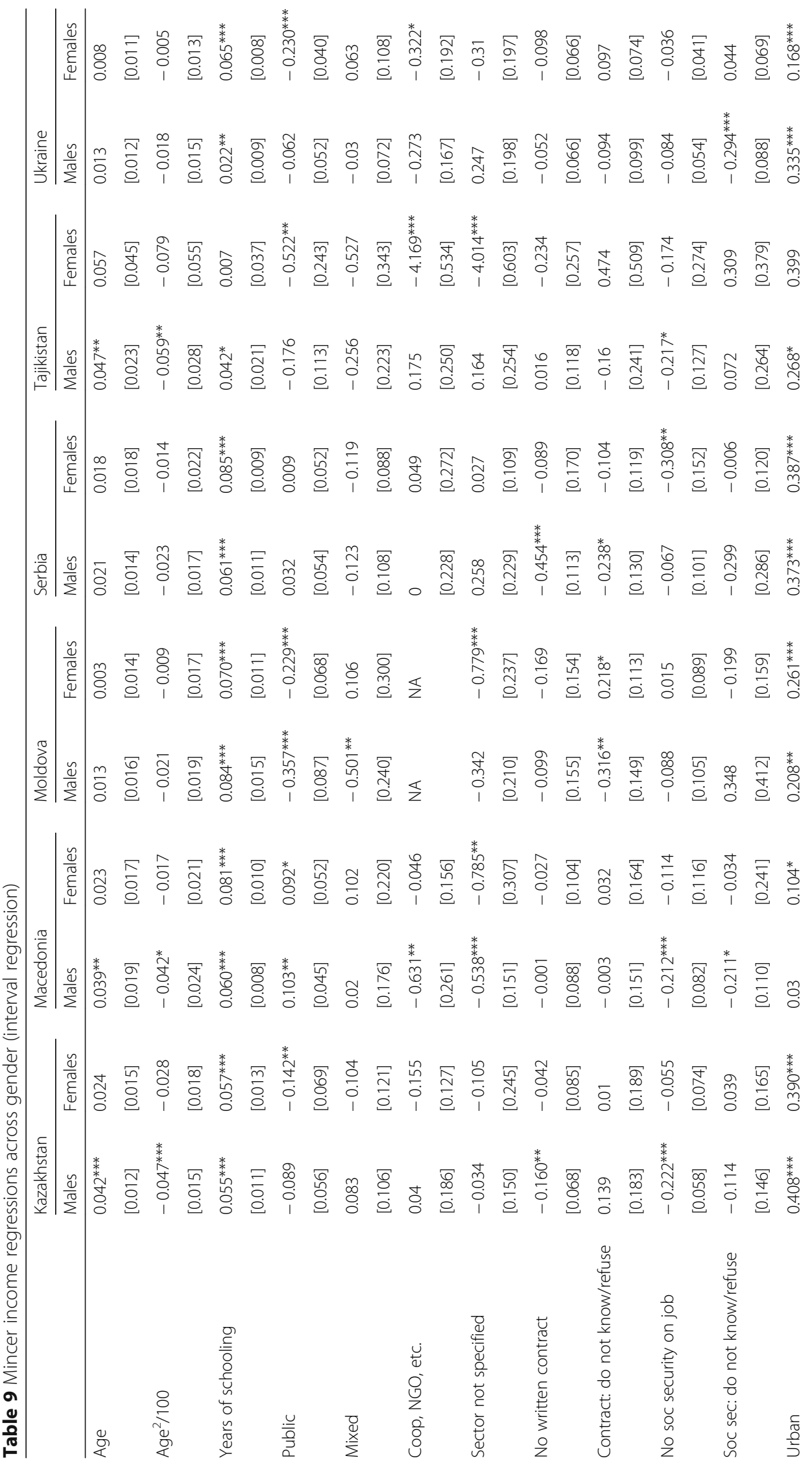




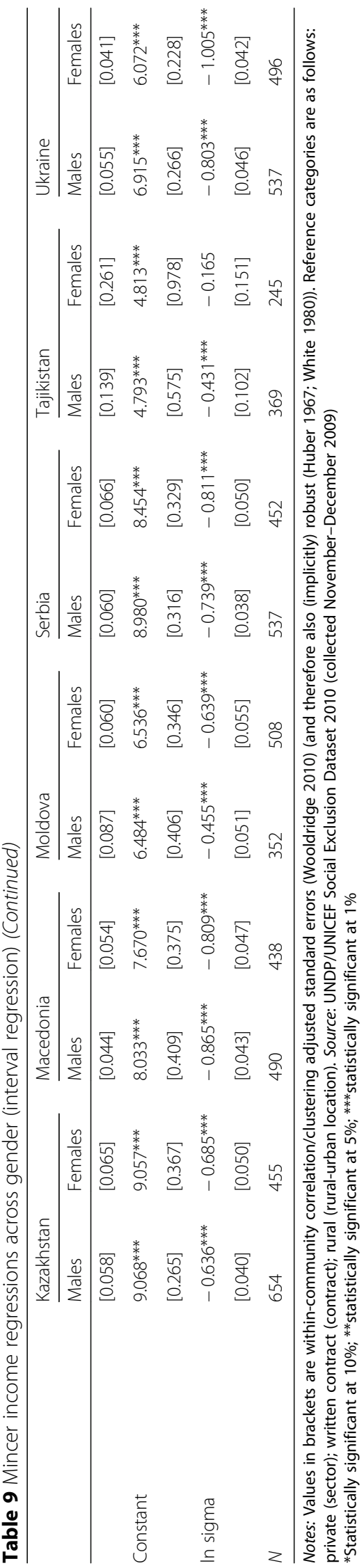




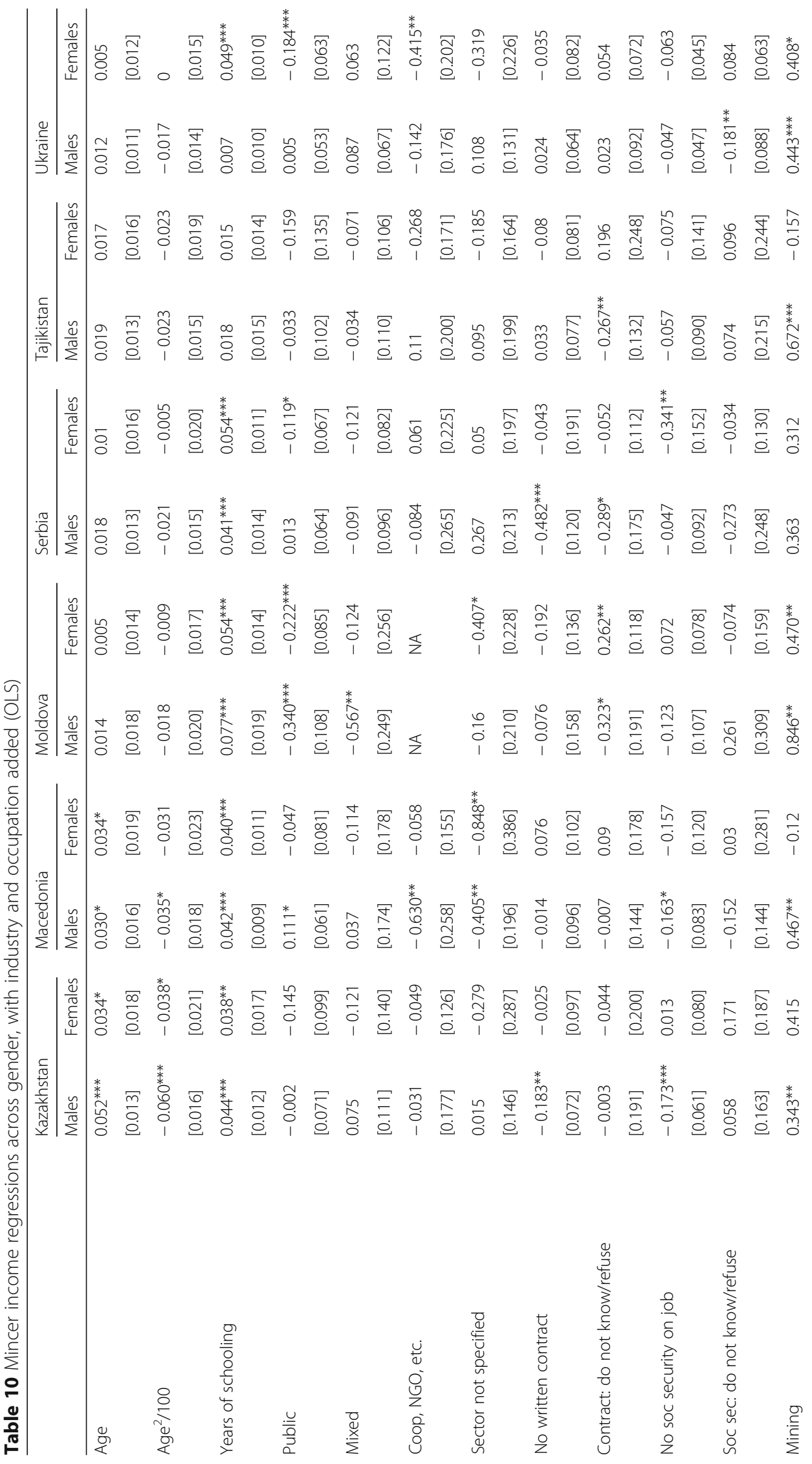




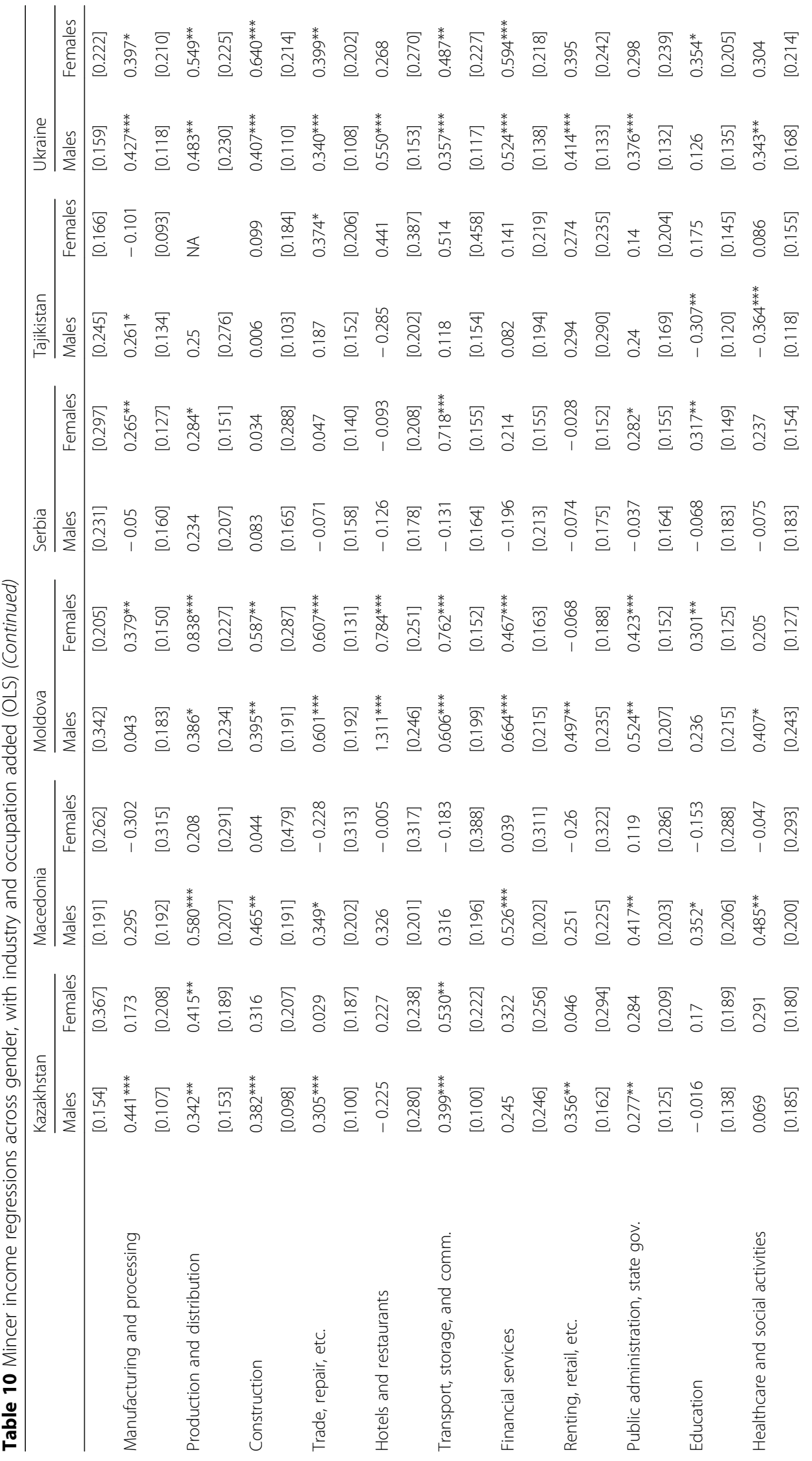




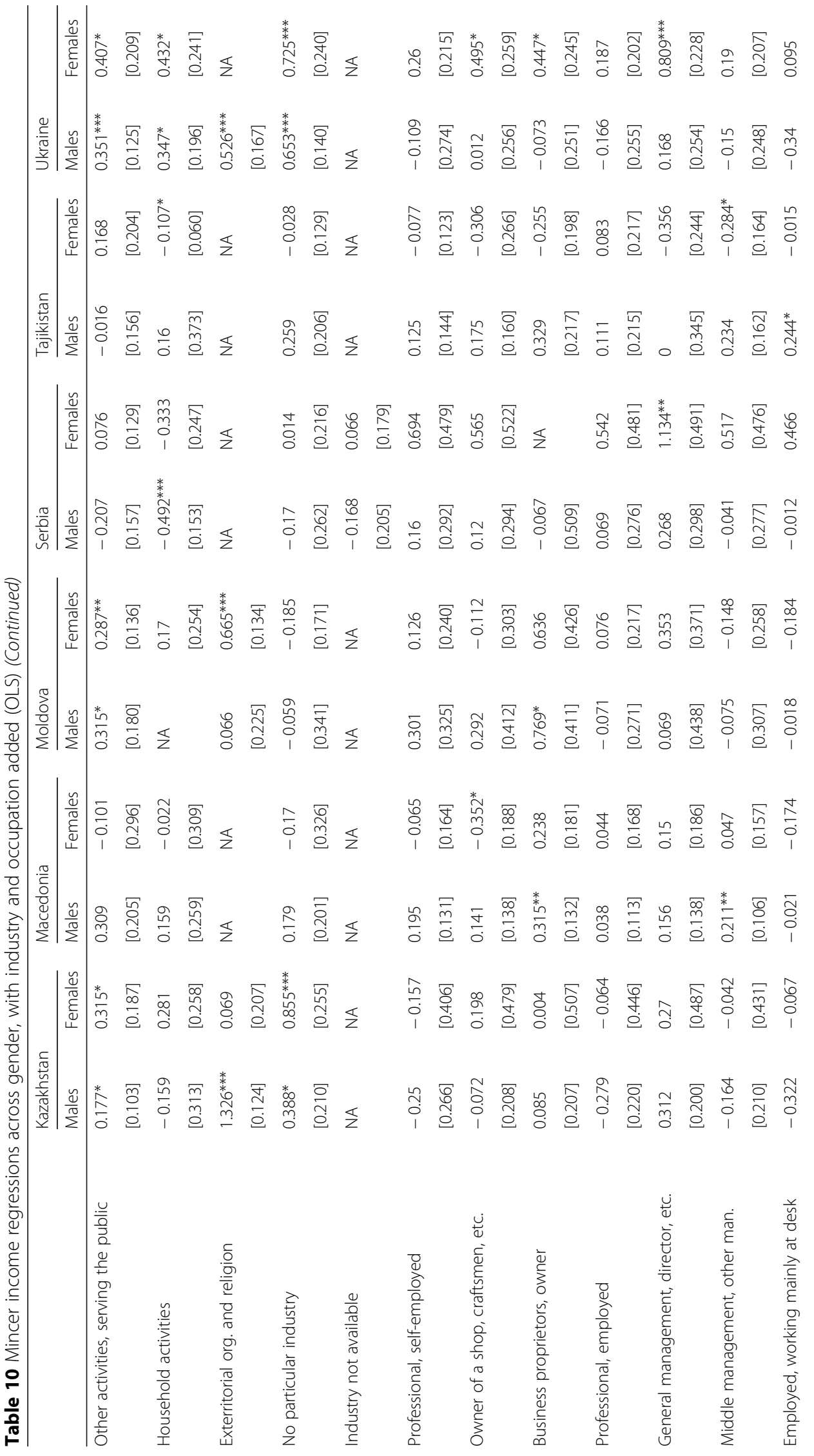




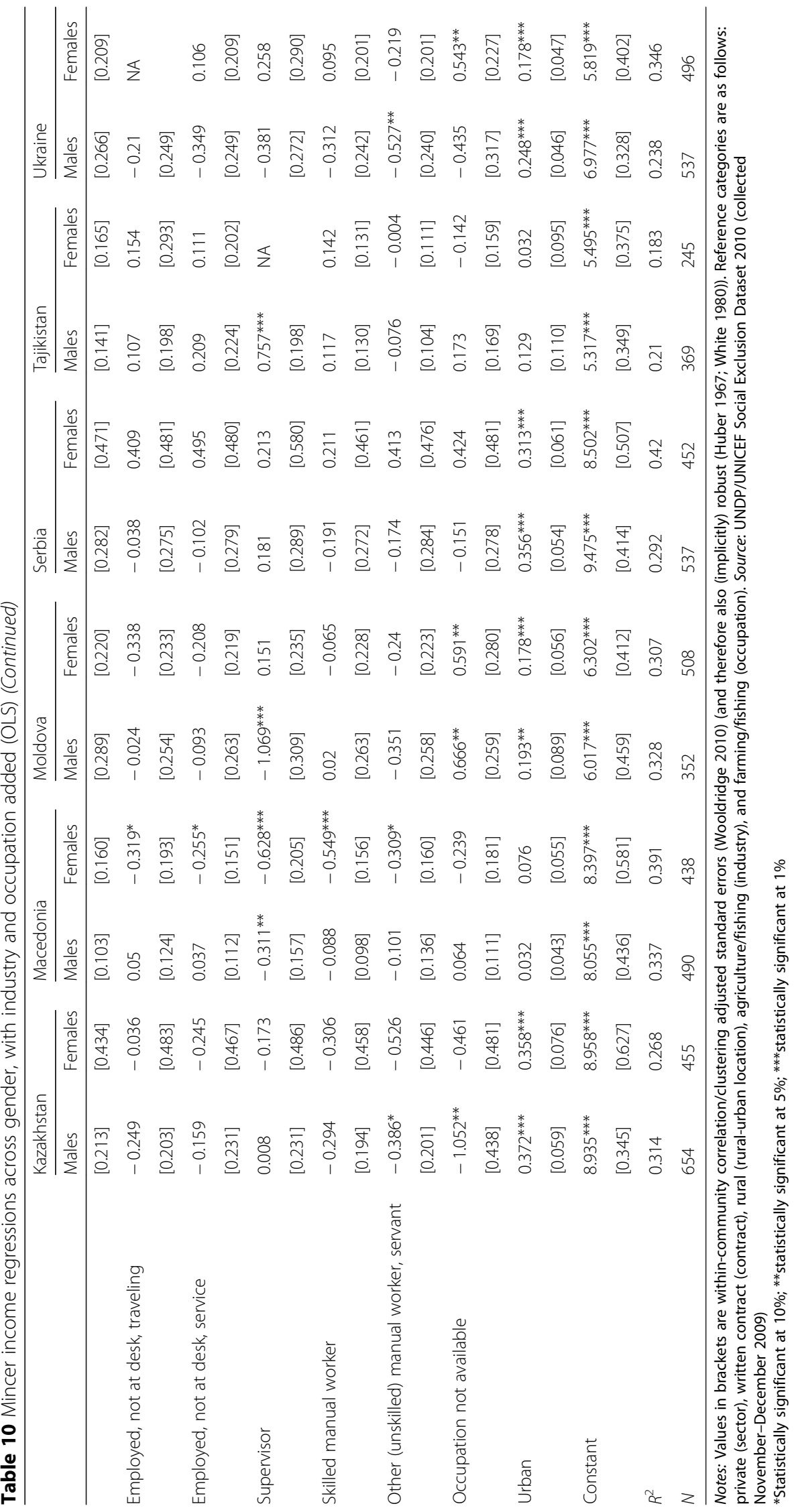




\section{Appendix 3}

\section{Testing for a glass ceiling using quantile regressions}

Table 11 Female quantile regression coefficients from pooled Mincer income regressions

\begin{tabular}{|c|c|c|c|c|c|c|c|}
\hline & \multicolumn{7}{|l|}{ Percentile } \\
\hline & 0.10 & 0.25 & 0.33 & 0.50 (median) & 0.67 & 0.75 & 0.90 \\
\hline \multicolumn{8}{|l|}{ Kazakhstan } \\
\hline \multirow[t]{2}{*}{ Female } & 0 & $-0.353^{* * *}$ & $-0.241^{* * *}$ & 0 & $-0.230^{* * *}$ & $-0.263^{* * *}$ & $-0.252^{* * *}$ \\
\hline & {$[0.054]$} & {$[0.080]$} & {$[0.064]$} & {$[0.044]$} & {$[0.044]$} & {$[0.050]$} & {$[0.060]$} \\
\hline \multicolumn{8}{|l|}{ Macedonia } \\
\hline \multirow[t]{2}{*}{ Female } & $-0.182^{* *}$ & $-0.182^{* * *}$ & $-0.200^{* * *}$ & $-0.166^{* * *}$ & $-0.190^{* * *}$ & $-0.213^{* * *}$ & $-0.128^{* * *}$ \\
\hline & {$[0.089]$} & {$[0.037]$} & {$[0.037]$} & {$[0.046]$} & {$[0.040]$} & {$[0.036]$} & {$[0.044]$} \\
\hline \multicolumn{8}{|l|}{ Moldova } \\
\hline \multirow[t]{2}{*}{ Female } & -0.093 & -0.076 & 0 & $0.000^{* * *}$ & 0 & -0.494 & $-0.421^{* * *}$ \\
\hline & {$[0.069]$} & {$[0.072]$} & {$[0.000]$} & {$[0.000]$} & {$[0.000]$} & {$[0.600]$} & {$[0.103]$} \\
\hline \multicolumn{8}{|l|}{ Serbia } \\
\hline \multirow[t]{2}{*}{ Female } & 0 & $-0.182^{* * *}$ & $-0.266^{* * *}$ & $-0.312^{* * *}$ & $-0.068^{*}$ & $-0.086^{* * *}$ & $-0.190^{* * *}$ \\
\hline & {$[0.050]$} & {$[0.052]$} & {$[0.052]$} & {$[0.041]$} & {$[0.041]$} & {$[0.032]$} & {$[0.053]$} \\
\hline \multicolumn{8}{|l|}{ Tajikistan } \\
\hline \multirow[t]{2}{*}{ Female } & 0 & 0 & 0 & 0 & 0 & -0.549 & -0.249 \\
\hline & {$[0.000]$} & {$[0.000]$} & {$[0.000]$} & {$[0.000]$} & {$[0.000]$} & {$[2.774]$} & [0.495] \\
\hline \multicolumn{8}{|l|}{ Ukraine } \\
\hline \multirow[t]{2}{*}{ Female } & $-0.208^{* * *}$ & $-0.298^{* * *}$ & $-0.294^{* * *}$ & $-0.361^{* * *}$ & $-0.280^{* * *}$ & $-0.523^{* * *}$ & 0 \\
\hline & {$[0.054]$} & {$[0.043]$} & {$[0.044]$} & {$[0.038]$} & {$[0.036]$} & {$[0.024]$} & {$[0.017]$} \\
\hline
\end{tabular}

\section{Appendix 4}

\section{Total threefold income decompositions: sensitivity analysis}

Table 12 Overall income decompositions, sensitivity analysis: threefold

\begin{tabular}{|c|c|c|c|c|c|c|}
\hline & Kazakhstan & Macedonia & Moldova & Serbia & Tajikistan & Ukraine \\
\hline \multicolumn{7}{|c|}{ (i) Decomposition from females' viewpoint, i.e., using male endowments and returns } \\
\hline \multirow[t]{2}{*}{ Endowments } & $-0.062^{* *}$ & -0.03 & 0.038 & $-0.070^{* * *}$ & 0.008 & -0.006 \\
\hline & {$[0.026]$} & {$[0.023]$} & {$[0.026]$} & {$[0.023]$} & {$[0.021]$} & {$[0.018]$} \\
\hline \multirow[t]{2}{*}{ Coefficients } & $0.293^{* * *}$ & $0.208^{* * *}$ & $0.201^{* * *}$ & $0.191^{* * *}$ & $0.141^{* * *}$ & $0.310^{* * *}$ \\
\hline & {$[0.041]$} & {$[0.033]$} & {$[0.053]$} & {$[0.031]$} & {$[0.045]$} & {$[0.032]$} \\
\hline \multirow[t]{2}{*}{ Interaction } & -0.025 & -0.003 & 0.016 & 0.023 & 0.024 & 0.001 \\
\hline & {$[0.023]$} & {$[0.018]$} & {$[0.028]$} & {$[0.015]$} & {$[0.026]$} & {$[0.018]$} \\
\hline \multicolumn{7}{|c|}{ (ii) Decomposition from males' viewpoint, i.e., using female endowments and returns } \\
\hline \multirow[t]{2}{*}{ Endowments } & $-0.087^{* * *}$ & $-0.032^{*}$ & $0.054^{*}$ & $-0.047^{* *}$ & 0.032 & -0.005 \\
\hline & {$[0.028]$} & {$[0.019]$} & {$[0.032]$} & {$[0.020]$} & {$[0.020]$} & {$[0.013]$} \\
\hline \multirow[t]{2}{*}{ Coefficients } & $0.268^{* * *}$ & $0.206^{* * *}$ & $0.217^{* * *}$ & $0.214^{* * *}$ & $0.164^{* * *}$ & $0.311^{* * *}$ \\
\hline & {$[0.043]$} & {$[0.034]$} & {$[0.052]$} & {$[0.032]$} & {$[0.049]$} & {$[0.032]$} \\
\hline \multirow[t]{2}{*}{ Interaction } & 0.025 & 0.003 & -0.016 & -0.023 & -0.024 & -0.001 \\
\hline & {$[0.023]$} & {$[0.018]$} & {$[0.028]$} & {$[0.015]$} & {$[0.026]$} & {$[0.018]$} \\
\hline$N$ & 1109 & 928 & 860 & 989 & 614 & 1033 \\
\hline
\end{tabular}

Notes: Values in brackets are within-community correlation/clustering adjusted standard errors (Wooldridge 2010) (and therefore also (implicitly) robust (Huber 1967; White 1980)). Source: UNDP/UNICEF Social Exclusion Dataset 2010 (collected November-December 2009) *: statistically significant at 10 percent; ${ }^{* *}$ : statistically significant at 5 percent; ${ }^{* * *}$ : statistically significant at 1 percent 


\section{Appendix 5}

\section{Total twofold income decompositions: sensitivity analysis}

Table 13 Overall income decompositions, sensitivity analysis: twofold

\begin{tabular}{|c|c|c|c|c|c|c|}
\hline & \multicolumn{6}{|c|}{$\begin{array}{l}\text { Weight given to males relative to females/regression model used in determining the reference } \\
\text { coefficients for decompositions: }\end{array}$} \\
\hline & $\begin{array}{l}0 \\
\text { (Oaxaca } \\
1973)\end{array}$ & $\begin{array}{l}1 \text { (Oaxaca 1973; } \\
\text { Blinder 1973) }\end{array}$ & $\begin{array}{l}0.5 \\
\text { (Reimers } \\
1983 \text { ) }\end{array}$ & $\begin{array}{l}\text { Share of males } \\
\text { (Cotton 1988) }\end{array}$ & $\begin{array}{l}\text { Pooled, excl. female } \\
\text { dummy (Neumark } \\
\text { 1988) }\end{array}$ & $\begin{array}{l}\text { Pooled, incl. female } \\
\text { dummy (Jann 2008) }\end{array}$ \\
\hline \multirow{3}{*}{ Explained } & & & & Kazakhstan & & \\
\hline & $-0.062^{* *}$ & $-0.087^{* * *}$ & $-\overline{0.074^{* * *}}$ & $-0.077^{* * *}$ & $-0.051^{* *}$ & $-0.076^{* * *}$ \\
\hline & {$[0.026]$} & {$[0.028]$} & {$[0.024]$} & {$[0.024]$} & {$[0.024]$} & {$[0.024]$} \\
\hline \multirow{2}{*}{ Unexplained } & $0.268^{* * *}$ & $0.293^{* * *}$ & $0.281^{* * *}$ & $0.283^{* * *}$ & $0.258^{* * *}$ & $0.282^{* * *}$ \\
\hline & {$[0.043]$} & {$[0.041]$} & {$[0.040]$} & {$[0.040]$} & {$[0.037]$} & {$[0.040]$} \\
\hline \multirow{3}{*}{ Explained } & & & & Macedonia & & \\
\hline & -0.03 & $-0.032^{*}$ & -0.031 & -0.031 & -0.028 & $-0.036^{*}$ \\
\hline & {$[0.023]$} & {$[0.019]$} & {$[0.019]$} & {$[0.019]$} & [0.019] & [0.019] \\
\hline \multirow{2}{*}{ Unexplained } & $0.206^{* * *}$ & $0.208^{* * *}$ & $0.207^{* * *}$ & $0.207^{* * *}$ & $0.204^{* * *}$ & $0.212^{* * *}$ \\
\hline & {$[0.034]$} & {$[0.033]$} & {$[0.032]$} & {$[0.032]$} & {$[0.031]$} & {$[0.032]$} \\
\hline \multirow{3}{*}{ Explained } & & & & Moldova & & \\
\hline & 0.038 & $0.054^{*}$ & $0.046^{*}$ & $0.045^{*}$ & $0.061^{* *}$ & $0.047^{*}$ \\
\hline & {$[0.026]$} & {$[0.032]$} & {$[0.026]$} & {$[0.025]$} & {$[0.025]$} & {$[0.025]$} \\
\hline \multirow{2}{*}{ Unexplained } & $0.217^{* * *}$ & $0.201^{* * *}$ & $0.209^{* * *}$ & $0.211^{* * *}$ & $0.195^{* * *}$ & $0.208^{* * *}$ \\
\hline & {$[0.052]$} & {$[0.053]$} & {$[0.051]$} & [0.051] & {$[0.047]$} & {$[0.051]$} \\
\hline \multirow{3}{*}{ Explained } & & & & Serbia & & \\
\hline & - & $-0.047^{* *}$ & - & $-0.058^{* * *}$ & $-0.053^{* * *}$ & $-0.059^{* * *}$ \\
\hline & {$[0.023]$} & {$[0.020]$} & {$[0.020]$} & {$[0.020]$} & {$[0.019]$} & {$[0.020]$} \\
\hline \multirow{2}{*}{ Unexplained } & $0.214^{* * *}$ & $0.191 * * *$ & $0.203^{* * *}$ & $0.202^{* * *}$ & $0.197^{* * *}$ & $0.204^{* * *}$ \\
\hline & {$[0.032]$} & {$[0.031]$} & {$[0.031]$} & {$[0.031]$} & {$[0.030]$} & {$[0.031]$} \\
\hline \multirow{3}{*}{ Explained } & & & & Tajikistan & & \\
\hline & 0.008 & 0.032 & 0.02 & 0.023 & $0.036^{* *}$ & 0.026 \\
\hline & {$[0.021]$} & {$[0.020]$} & {$[0.016]$} & {$[0.016]$} & {$[0.017]$} & {$[0.016]$} \\
\hline \multirow{2}{*}{ Unexplained } & $0.164^{* * *}$ & $0.141^{* * *}$ & $0.153^{* * *}$ & $0.150^{* * *}$ & $0.137^{* * *}$ & $0.147^{* * *}$ \\
\hline & {$[0.049]$} & {$[0.045]$} & {$[0.045]$} & {$[0.045]$} & {$[0.042]$} & {$[0.045]$} \\
\hline \multirow{3}{*}{ Explained } & & & & Ukraine & & \\
\hline & -0.006 & -0.005 & -0.005 & -0.005 & 0.011 & -0.005 \\
\hline & {$[0.018]$} & [0.013] & {$[0.013]$} & {$[0.013]$} & [0.013] & [0.013] \\
\hline \multirow{2}{*}{ Unexplained } & $0.311^{* * *}$ & $0.310^{* * *}$ & $0.310^{* * *}$ & $0.310^{* * *}$ & $0.294^{* * *}$ & $0.310^{* * *}$ \\
\hline & [0.032] & {$[0.032]$} & {$[0.031]$} & {$[0.031]$} & {$[0.029]$} & {$[0.031]$} \\
\hline
\end{tabular}

Notes: The numbers of observations are Kazakhstan =1109, Macedonia =928, Moldova =860, Serbia = 989, Tajikistan $=614$, and Ukraine $=1033$. Values in brackets are within-community correlation/clustering adjusted standard errors (Wooldridge 2010) (and therefore also (implicitly) robust (Huber 1967; White 1980)). Source: UNDP/UNICEF Social Exclusion Dataset 2010 (collected November-December 2009)

${ }^{*}$ : statistically significant at 10 percent; ${ }^{* *}$ : statistically significant at 5 percent; ${ }^{* * *}$ : statistically significant at 1 percent 


\section{Appendix 6}

\section{Detailed threefold income decompositions}

Table 14 Detailed threefold income decompositions: Kazakhstan

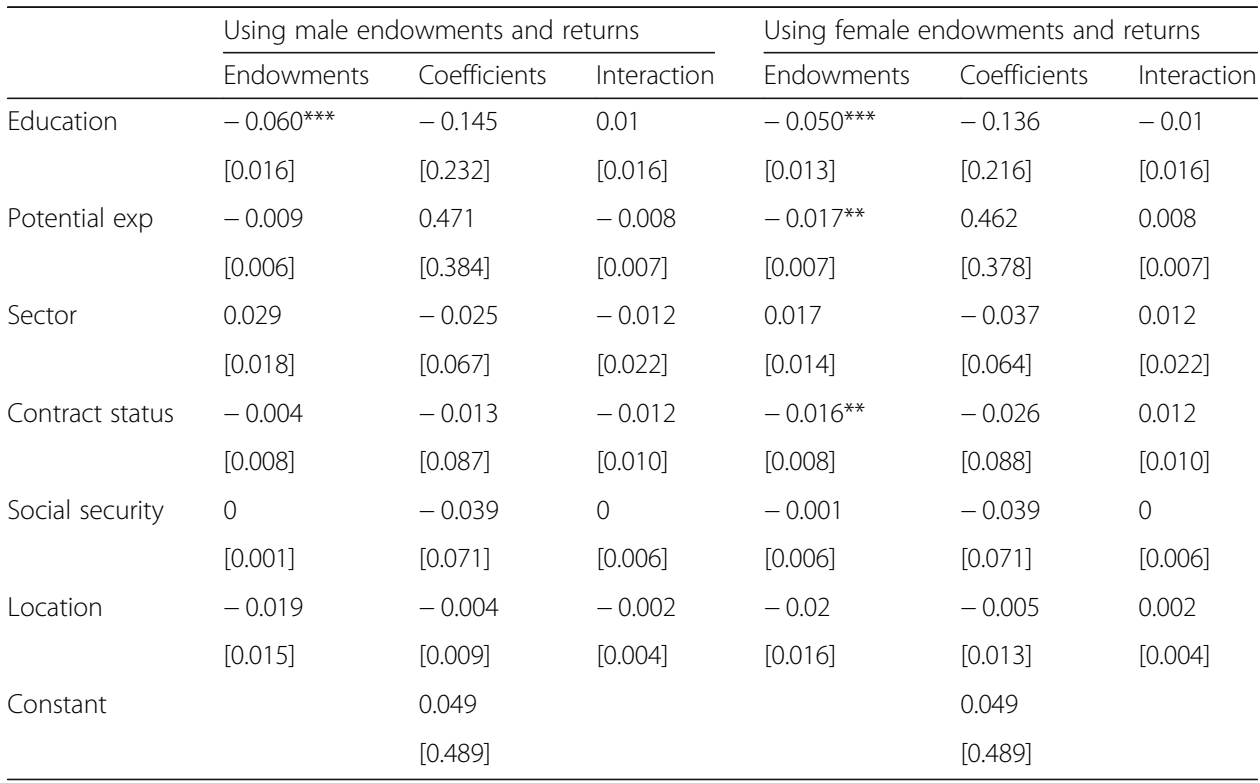

Notes: Values in brackets are within-community correlation/clustering adjusted standard errors (Wooldridge 2010) (and therefore also (implicitly) robust (Huber 1967; White 1980)), computed according to Jann (2008). Source: UNDP/UNICEF Social Exclusion Dataset 2010 (collected November-December 2009)

*Statistically significant at $10 \%$; ${ }^{* *}$ statistically significant at $5 \%$; ${ }^{* * *}$ statistically significant at $1 \%$

Table 15 Detailed threefold income decompositions: Macedonia

\begin{tabular}{|c|c|c|c|c|c|c|}
\hline & \multicolumn{3}{|c|}{ Using male endowments and returns } & \multicolumn{3}{|c|}{ Using female endowments and returns } \\
\hline & Endowments & Coefficients & Interaction & Endowments & Coefficients & Interaction \\
\hline \multirow[t]{2}{*}{ Education } & -0.022 & $-0.294^{*}$ & 0.006 & -0.016 & $-0.287^{*}$ & -0.006 \\
\hline & {$[0.014]$} & {$[0.168]$} & {$[0.005]$} & {$[0.010]$} & {$[0.164]$} & {$[0.005]$} \\
\hline \multirow[t]{2}{*}{ Potential exp } & 0.016 & 0.078 & -0.017 & -0.001 & 0.061 & 0.017 \\
\hline & {$[0.010]$} & {$[0.510]$} & {$[0.010]$} & {$[0.008]$} & {$[0.505]$} & {$[0.010]$} \\
\hline \multirow[t]{2}{*}{ Sector } & $-0.022^{* *}$ & 0.091 & 0.016 & -0.005 & 0.107 & -0.016 \\
\hline & {$[0.011]$} & {$[0.107]$} & {$[0.011]$} & {$[0.011]$} & {$[0.107]$} & {$[0.011]$} \\
\hline \multirow[t]{2}{*}{ Contract status } & 0.003 & 0.038 & -0.005 & -0.002 & 0.033 & 0.005 \\
\hline & {$[0.006]$} & {$[0.086]$} & {$[0.008]$} & {$[0.005]$} & {$[0.079]$} & {$[0.008]$} \\
\hline \multirow[t]{2}{*}{ Social security } & -0.005 & 0.067 & -0.003 & -0.009 & 0.064 & 0.003 \\
\hline & {$[0.006]$} & {$[0.096]$} & {$[0.006]$} & {$[0.005]$} & {$[0.093]$} & {$[0.006]$} \\
\hline \multirow[t]{2}{*}{ Location } & 0.001 & 0.001 & -0.001 & 0 & 0 & 0.001 \\
\hline & {$[0.004]$} & {$[0.003]$} & {$[0.003]$} & {$[0.001]$} & {$[0.002]$} & {$[0.003]$} \\
\hline \multirow[t]{2}{*}{ Constant } & & 0.228 & & & 0.228 & \\
\hline & & {$[0.569]$} & & & {$[0.569]$} & \\
\hline
\end{tabular}

Notes: Values in brackets are within-community correlation/clustering adjusted standard errors (Wooldridge 2010) (and therefore also (implicitly) robust (Huber 1967; White 1980)), computed according to Jann (2008). Source: UNDP/UNICEF Social Exclusion Dataset 2010 (collected November-December 2009)

*Statistically significant at $10 \%$; **statistically significant at $5 \%$; ${ }^{* * *}$ statistically significant at $1 \%$ 
Table 16 Detailed three-fold income decompositions: Moldova

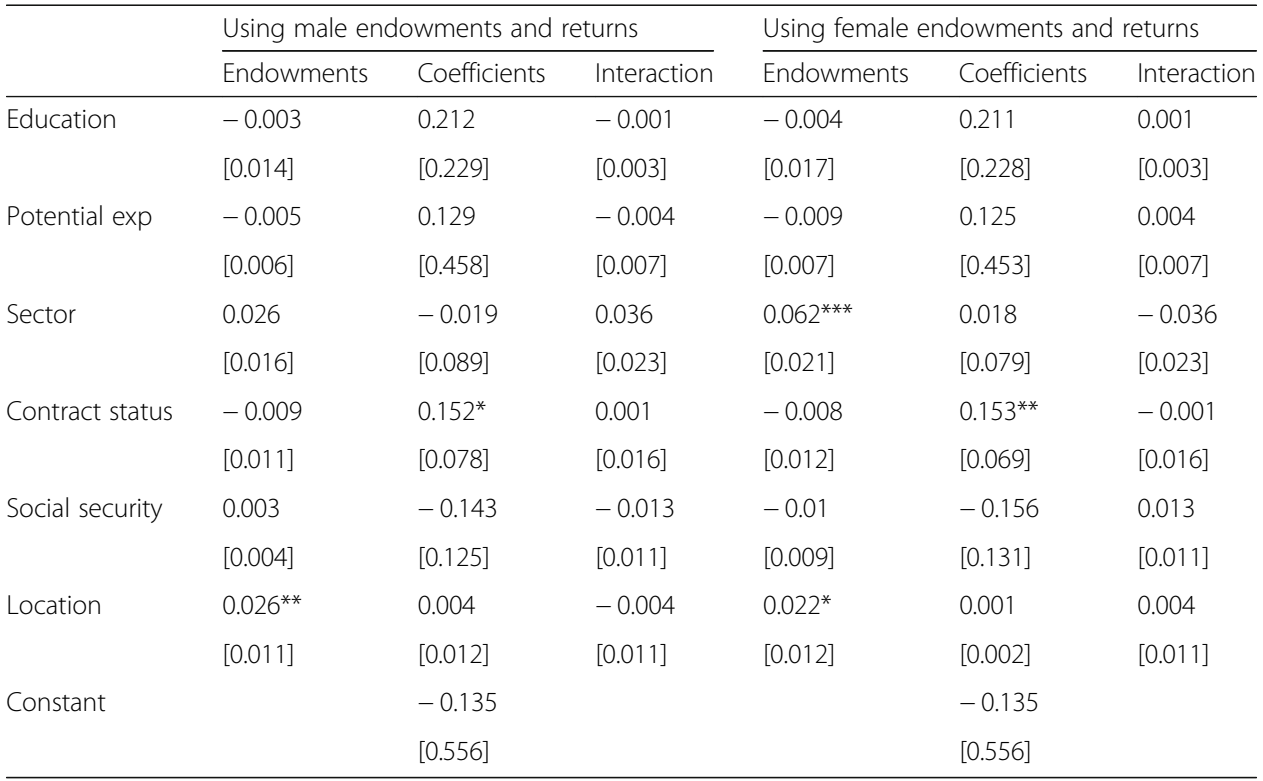

Notes: Values in brackets are within-community correlation/clustering adjusted standard errors (Wooldridge 2010) (and therefore also (implicitly) robust (Huber 1967; White 1980)), computed according to Jann (2008). Source: UNDP/UNICEF Social Exclusion Dataset 2010 (collected November-December 2009)

*Statistically significant at $10 \%$; **statistically significant at $5 \%$; ***statistically significant at $1 \%$

Table 17 Detailed threefold income decompositions: Serbia

\begin{tabular}{|c|c|c|c|c|c|c|}
\hline & \multicolumn{3}{|c|}{ Using male endowments and returns } & \multicolumn{3}{|c|}{ Using female endowments and returns } \\
\hline & Endowments & Coefficients & Interaction & Endowments & Coefficients & Interaction \\
\hline \multirow[t]{2}{*}{ Education } & $-0.063^{* * *}$ & $-0.322^{*}$ & $0.020^{*}$ & $-0.044^{* * *}$ & $-0.303^{*}$ & $-0.020^{*}$ \\
\hline & {$[0.016]$} & {$[0.174]$} & {$[0.011]$} & {$[0.013]$} & {$[0.163]$} & {$[0.011]$} \\
\hline \multirow[t]{2}{*}{ Potential exp } & 0.002 & -0.014 & -0.003 & -0.002 & -0.017 & 0.003 \\
\hline & {$[0.006]$} & {$[0.450]$} & {$[0.006]$} & {$[0.004]$} & {$[0.446]$} & {$[0.006]$} \\
\hline \multirow[t]{2}{*}{ Sector } & 0 & -0.007 & -0.001 & -0.002 & -0.008 & 0.001 \\
\hline & {$[0.003]$} & {$[0.081]$} & {$[0.004]$} & {$[0.003]$} & {$[0.079]$} & {$[0.004]$} \\
\hline \multirow[t]{2}{*}{ Contract status } & 0 & $0.167^{* *}$ & -0.002 & -0.002 & $0.165^{*}$ & 0.002 \\
\hline & {$[0.002]$} & {$[0.085]$} & {$[0.006]$} & {$[0.006]$} & {$[0.084]$} & {$[0.006]$} \\
\hline \multirow[t]{2}{*}{ Social security } & -0.01 & 0.015 & 0.011 & 0.001 & 0.026 & -0.011 \\
\hline & {$[0.009]$} & {$[0.093]$} & {$[0.008]$} & {$[0.005]$} & {$[0.094]$} & {$[0.008]$} \\
\hline \multirow[t]{2}{*}{ Location } & 0.002 & 0.005 & 0 & 0.002 & 0.004 & 0 \\
\hline & {$[0.009]$} & {$[0.011]$} & {$[0.001]$} & {$[0.008]$} & {$[0.011]$} & {$[0.001]$} \\
\hline \multirow[t]{2}{*}{ Constant } & & 0.347 & & & 0.347 & \\
\hline & & {$[0.479]$} & & & {$[0.479]$} & \\
\hline
\end{tabular}

Notes: Values in brackets are within-community correlation/clustering adjusted standard errors (Wooldridge 2010) (and therefore also (implicitly) robust (Huber 1967; White 1980)), computed according to Jann (2008). Source: UNDP/UNICEF Social Exclusion Dataset 2010 (collected November-December 2009)

*Statistically significant at $10 \%$; **statistically significant at $5 \%$; ***statistically significant at $1 \%$ 
Table 18 Detailed Three-fold Income Decompositions: Tajikistan

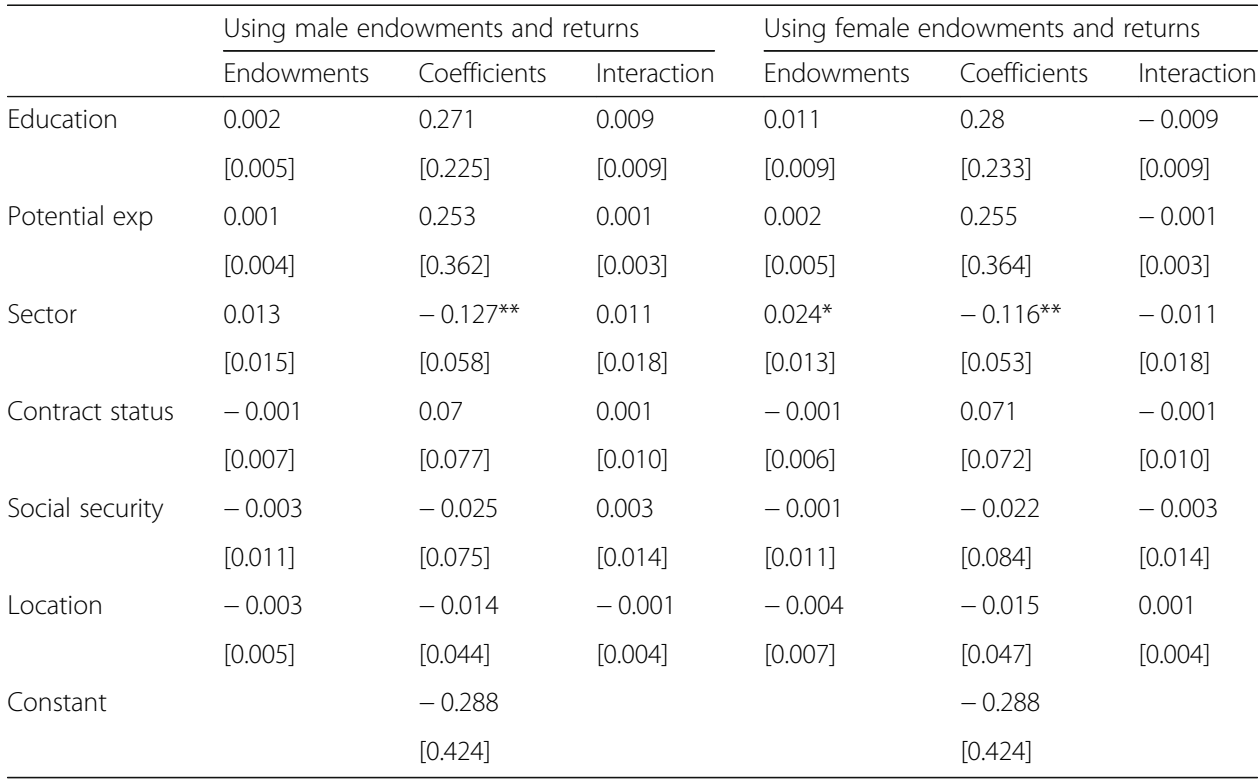

Notes: Values in brackets are within-community correlation/clustering adjusted standard errors (Wooldridge 2010) (and therefore also (implicitly) robust (Huber 1967; White 1980)), computed according to Jann (2008). Source: UNDP/UNICEF Social Exclusion Dataset 2010 (collected November-December 2009)

*Statistically significant at $10 \%$; ${ }^{* *}$ statistically significant at $5 \%$; ${ }^{* * *}$ statistically significant at $1 \%$

Table 19 Detailed threefold income decompositions: Ukraine

\begin{tabular}{|c|c|c|c|c|c|c|}
\hline & \multicolumn{3}{|c|}{ Using male endowments and returns } & \multicolumn{3}{|c|}{ Using female endowments and returns } \\
\hline & Endowments & Coefficients & Interaction & Endowments & Coefficients & Interaction \\
\hline \multirow[t]{2}{*}{ Education } & $-0.029^{* *}$ & $-0.702^{* * *}$ & $0.022^{* *}$ & $-0.008^{*}$ & $-0.681^{* * *}$ & $-0.022^{* *}$ \\
\hline & {$[0.012]$} & {$[0.158]$} & {$[0.009]$} & {$[0.004]$} & {$[0.153]$} & {$[0.009]$} \\
\hline \multirow[t]{2}{*}{ Potential exp } & $-0.010^{* *}$ & -0.123 & $0.013^{*}$ & 0.003 & -0.11 & $-0.013^{*}$ \\
\hline & {$[0.005]$} & [0.319] & {$[0.007]$} & {$[0.004]$} & {$[0.317]$} & {$[0.007]$} \\
\hline \multirow[t]{2}{*}{ Sector } & $0.047^{* * *}$ & -0.079 & $-0.040^{* * *}$ & 0.007 & -0.119 & $0.040^{* * *}$ \\
\hline & {$[0.012]$} & [0.092] & {$[0.014]$} & {$[0.009]$} & {$[0.090]$} & {$[0.014]$} \\
\hline \multirow[t]{2}{*}{ Contract status } & -0.004 & 0.03 & 0.003 & -0.001 & 0.033 & -0.003 \\
\hline & {$[0.004]$} & {$[0.044]$} & {$[0.004]$} & {$[0.002]$} & {$[0.042]$} & {$[0.004]$} \\
\hline \multirow[t]{2}{*}{ Social security } & -0.002 & $0.074^{* * *}$ & 0.007 & 0.005 & $0.081^{* * *}$ & -0.007 \\
\hline & {$[0.003]$} & {$[0.027]$} & {$[0.005]$} & {$[0.004]$} & {$[0.029]$} & {$[0.005]$} \\
\hline \multirow[t]{2}{*}{ Location } & -0.007 & -0.013 & -0.004 & -0.011 & $-0.017^{*}$ & 0.004 \\
\hline & {$[0.005]$} & {$[0.008]$} & {$[0.003]$} & {$[0.008]$} & {$[0.010]$} & {$[0.003]$} \\
\hline \multirow[t]{2}{*}{ Constant } & & $1.123^{* * *}$ & & & $1.123^{* * *}$ & \\
\hline & & {$[0.368]$} & & & {$[0.368]$} & \\
\hline
\end{tabular}

Notes: Values in brackets are within-community correlation/clustering adjusted standard errors (Wooldridge 2010) (and therefore also (implicitly) robust (Huber 1967; White 1980)), computed according to Jann (2008). Source: UNDP/UNICEF Social Exclusion Dataset 2010 (collected November-December 2009)

*Statistically significant at $10 \%$; **statistically significant at $5 \%$; ***statistically significant at $1 \%$ 


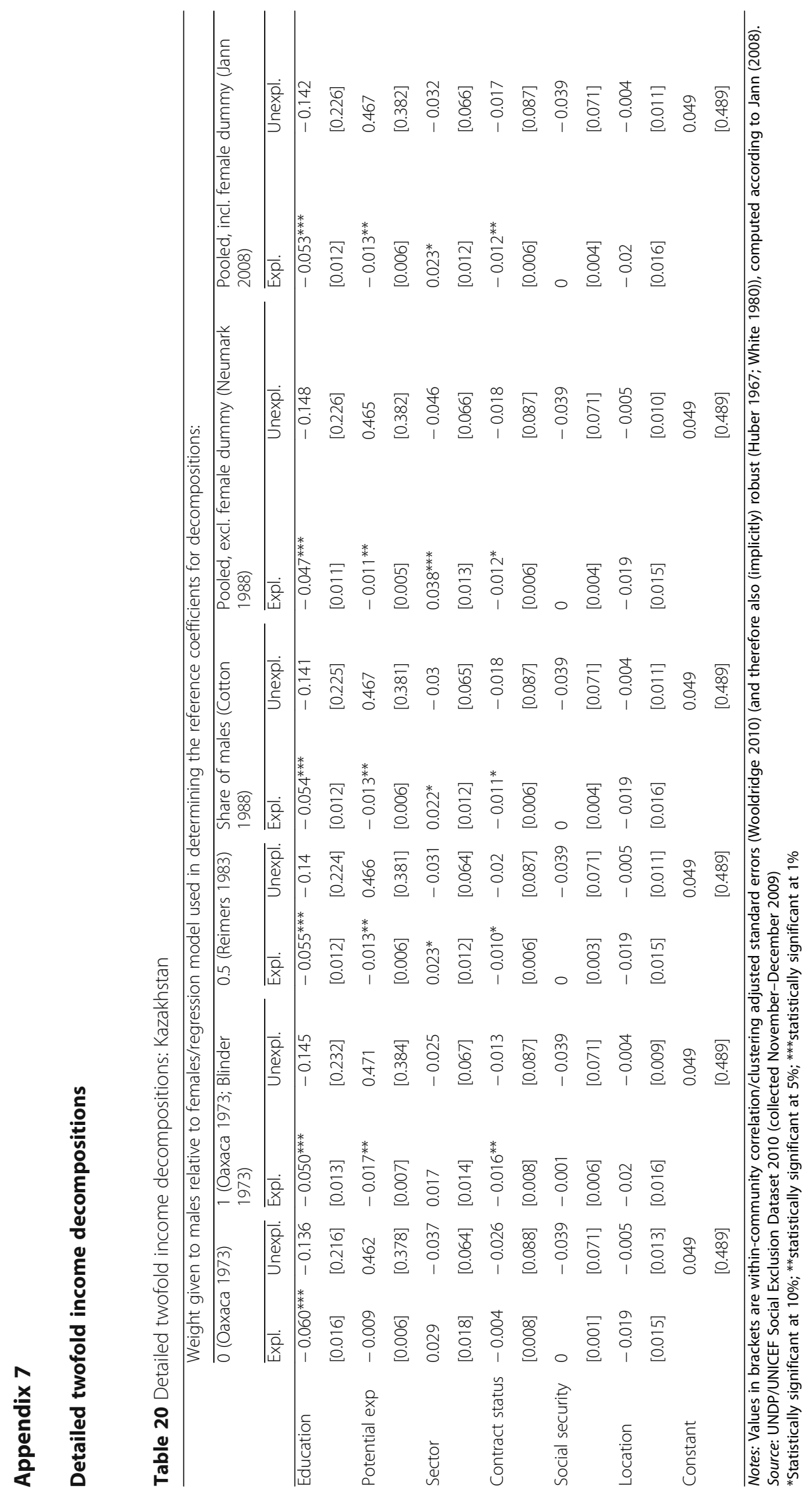




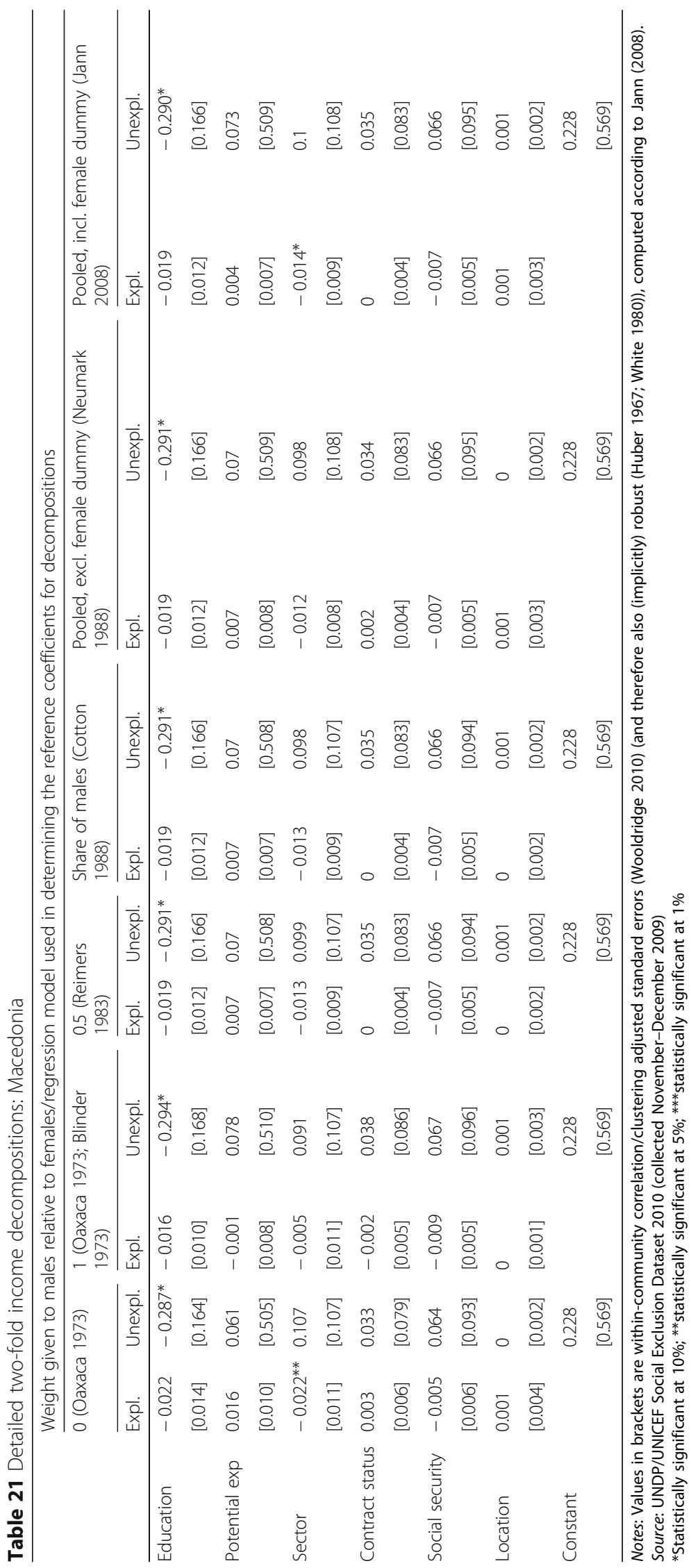




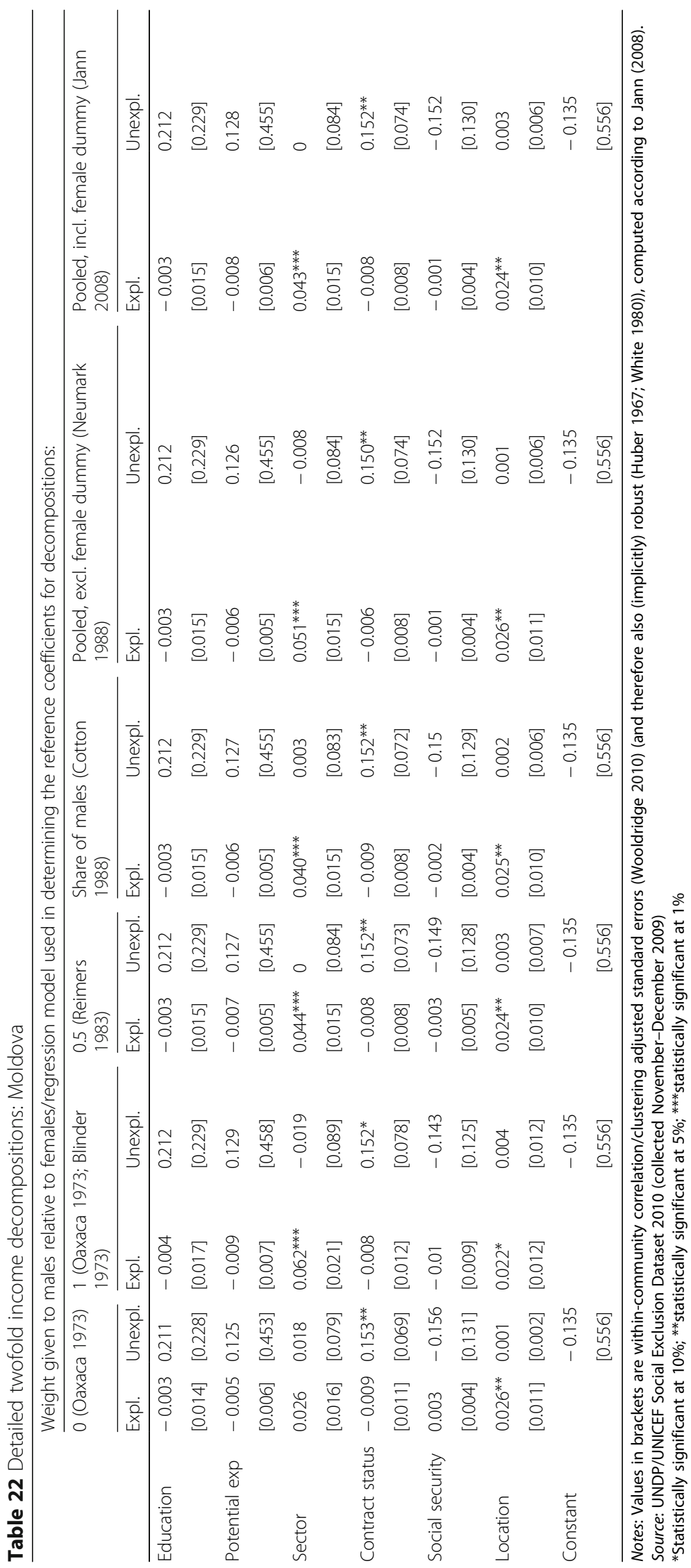




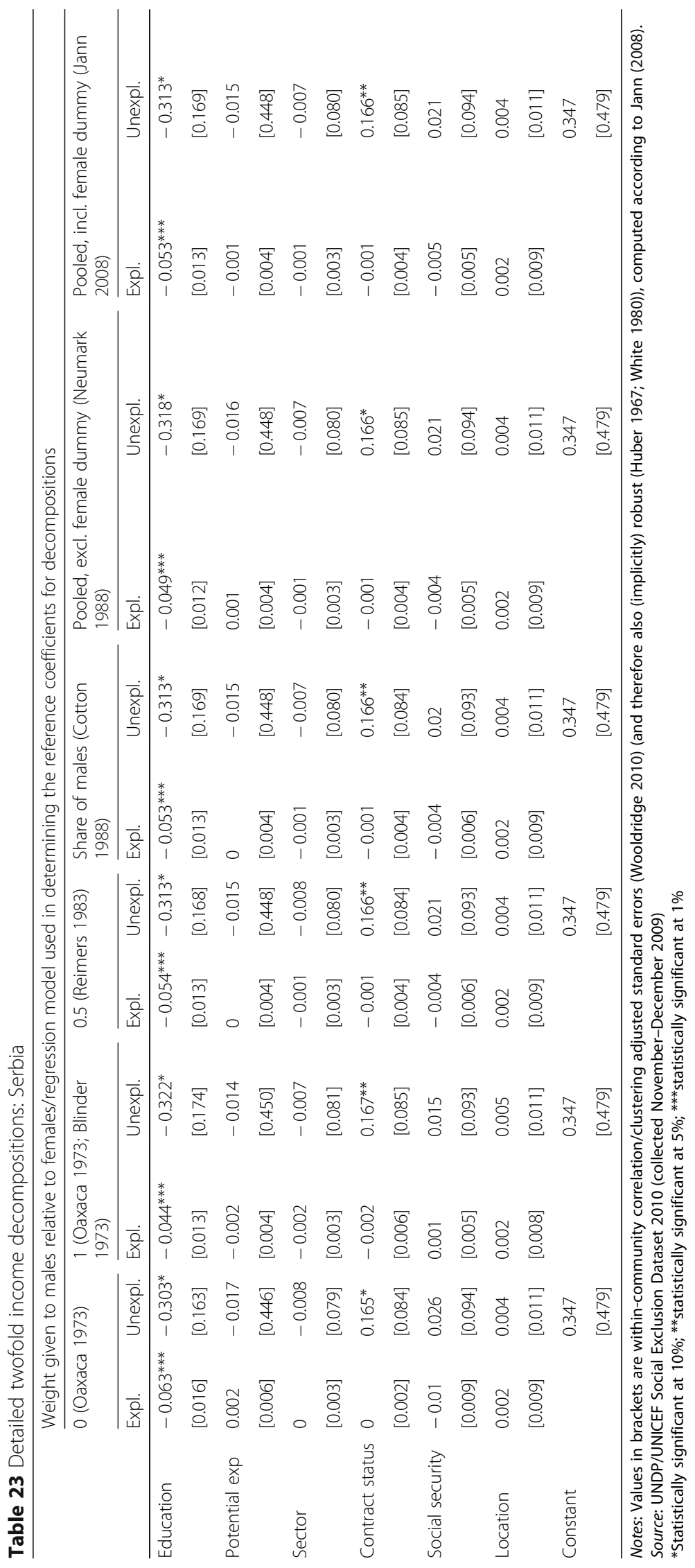




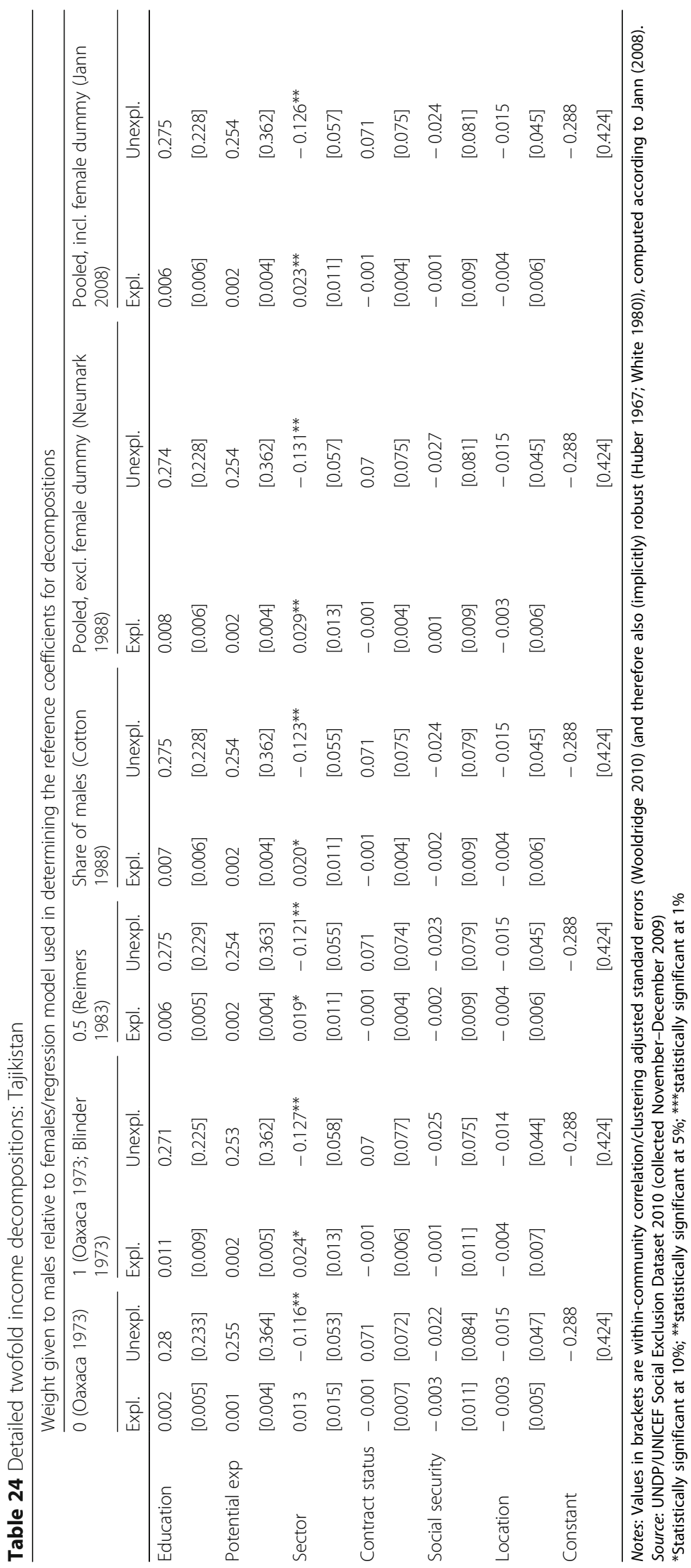




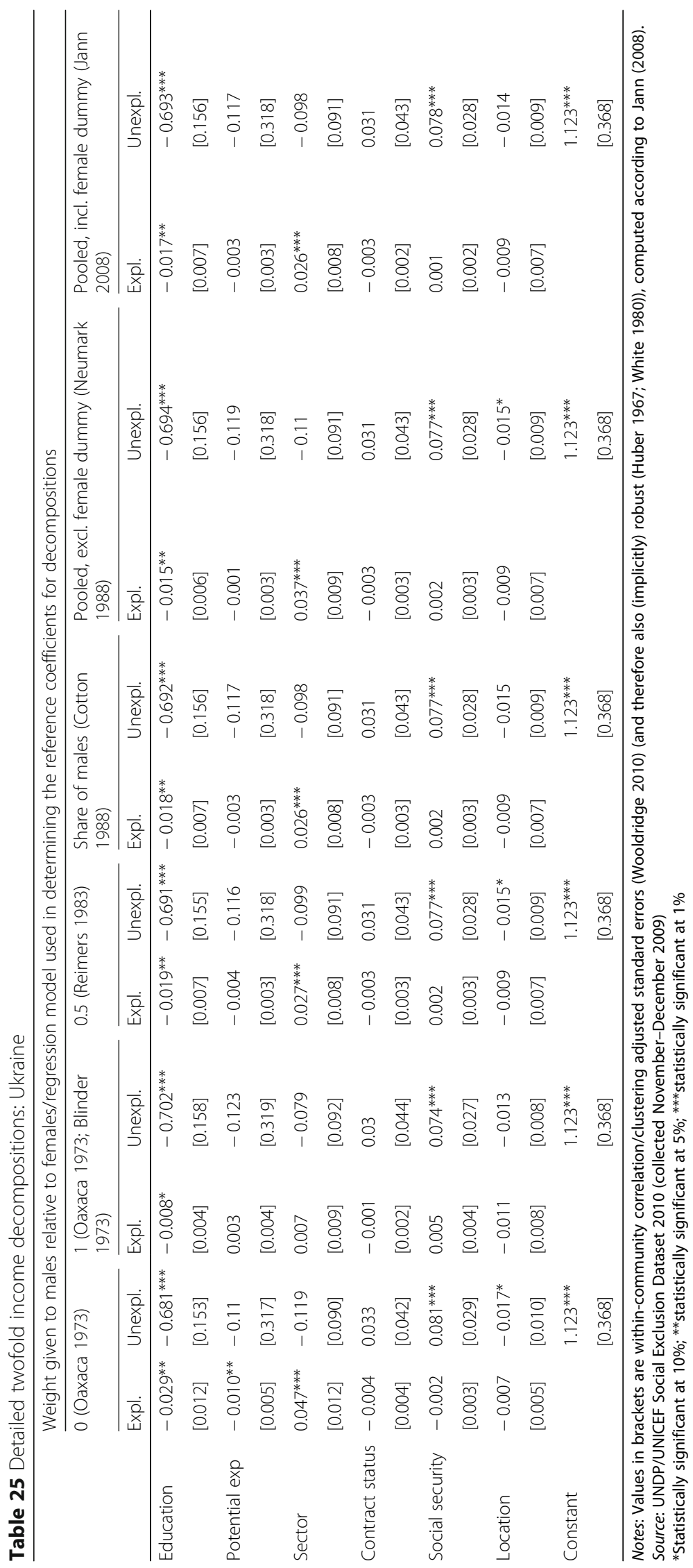




\section{Acknowledgements}

This manuscript is based on a background paper commissioned by the World Bank's Poverty Reduction and Economic Management Unit, Europe and Central Asia Region Department. I thank Mihail Arandarenko, David Ribar, Victor Sulla, and the participants at the first GRAPE Gender Gaps Conference for their helpful comments and suggestions and Victor Sulla and Caterina Ruggeri Laderchi for their managerial support. Remaining errors and omissions are my own. The data were kindly provided by the United Nations Development Program (UNDP). Assistance from Susanne Milcher, UNDP, helped me understand the data better and is greatly appreciated. I would like to thank the anonymous referee and the editor for the useful remarks. The findings and interpretations are those of the author and should not be attributed to the World Bank, the United Nations Development Program, or any affiliated institutions.

Responsible editor: Hartmut F. Lehmann.

\section{Funding}

This manuscript is based on a background paper commissioned and funded by the World Bank's Poverty Reduction and Economic Management Unit, Europe and Central Asia Region Department. The World Bank ECA Department, however, was not involved in the design of the study, nor in the collection, analysis, and interpretation of data, or in writing the manuscript.

\section{Availability of data and materials}

The data examined here is proprietary to the UNDP but was obtained and should, according to a UNDP Report, still be obtainable upon request via the following Website: http://europeandcis.undp.org/poverty/socialinclusion (when I last checked, this page seemed to have been removed, however). For more details, the UNDP Report can be downloaded from (as of January 14, 2018): http://www.eurasia.undp.org/content/rbec/en/home/library/poverty/ Regional_Human_Development_Report_on_social_inclusion.html?download.

\section{Authors' information}

The author is an Associate Professor at the Economics Department at Washington and Lee University in Lexington, Virginia, USA.

\section{Ethics approval and consent to participate}

Not applicable

\section{Consent for publication}

Not applicable

\section{Competing interests}

The IZA Journal of Development and Migration is committed to the IZA Guiding Principles of Research Integrity. The author declares that he has observed these principles.

\section{Publisher's Note}

Springer Nature remains neutral with regard to jurisdictional claims in published maps and institutional affiliations.

Received: 13 April 2017 Accepted: 27 December 2017

Published online: 14 June 2018

\section{References}

Abdurazakova D. National mechanisms for gender equality in South-East and Eastern Europe, Caucasus and Central Asia. New York: United Nations Economic Commission for Europe; 2010

Albrecht J, Björklund A, Vroman S. Is there a glass ceiling in Sweden? J Labor Econ. 2003;21(1):145-77.

Altonji JG, Blank RM. Race and gender in the labor market. In: Ashenfelter O, Card D, editors. Handbook of labor economics, vol. 3. Amsterdam: Elsevier; 1999.

Babović M. The position of women on the labour market in Serbia. Belgrade: Gender Equality Council, Government of the Republic of Serbia and United Nations Development Programme, Serbia; 2008.

Becker GS. Human Capital. Chicago: University of Chicago Press; 1964.

Blau FD. The gender pay gap. In: Persson I, Jonung C, editors. Women's work and wages. London: Routledge; 1998.

Blau FD, Kahn LM. The gender earnings gap: learning from international comparison. Am Econ Rev Pap Proc. 1992; 82(2):533-8.

Blau FD, Kahn LM. Wage structure and gender earnings differential: an international comparison. Economica Suppl. 1996;63(250):S29-62

Blau FD, Kahn LM. Swimming upstream: trends in the gender wage differential in the 1980's. J Labor Econ. 1997;15(1):1-42. Blau FD, Kahn LM. Gender differences in pay. J Econ Perspect. 2000;14(4):75-99.

Blau FD, Kahn LM. Understanding international differences in the gender pay gap. J Labor Econ. 2003;21(1):106-44.

Blinder AS. Wage discrimination: reduced form and structural estimates. J Hum Resour. 1973;8:436-55.

Blunch, Niels-Hugo and Victor Sulla (2010) The financial crisis, labor market transitions and earnings growth: a gendered panel data analysis for Serbia, background paper, Poverty Reduction and Economic Management Unit, Europe and Central Asia Region Department, Washington, DC: World Bank.

Brainerd E. Women in transition: changes in gender wage differentials in Eastern Europe and the former soviet union. Ind Labor Relat Rev. 2000:54(1):138-62.

Cameron AC, Trivedi PK. Microeconometrics using Stata. Revised ed. College Station: Stata Press; 2010. 
Cho D, Cho J. How do labor unions influence the gender earnings gap? A comparative study of the US and Korea. Fem Econ. 2011;17(3):133-57.

Cotton J. On the decomposition of wage differentials. Rev Econ Stat. 1988;70:236-43.

Grajek M. Gender pay gap in Poland. Econ Plan. 2003;36:23-44.

Heckman JJ, Lochner LJ, Todd PE. Earnings functions and rates of return. J Hum Cap. 2008;2(1):1-31.

Huber PJ. The behavior of maximum likelihood estimates under nonstandard conditions. In: Le Cam LM, Neyman J,

editors. Proceedings of the Fifth Berkeley Symposium on Mathematical Statistics and Probability, vol. 1. Berkeley: University of California Press; 1967

Hunt J. The transition in East Germany: when is a ten point-fall in the gender gap bad news? J Labor Econ. 2002;20(1):148-69.

Jann B. The Blinder-Oaxaca decomposition for linear regression models. Stata J. 2008;8(4):453-79.

Kish L. A procedure for objective respondent selection within the household. J Am Stat Assoc. 1949;44(247):380-7.

Kuddo A. Employment services and active labor market programs in Eastern European and Central Asian countries, social protection discussion paper no. 0918. Washington, DC: World Bank; 2009.

Mincer J. Schooling, experience and earnings. New York: National Bureau of Economic Research; 1974.

Neumark D. Employers' discriminatory behavior and the estimation of wage discrimination. J Hum Resour. 1988;23:279-95.

Newell A, Reilly B. The gender pay gap in the transition from communism: some empirical evidence. Econ Syst. 2001; 25(4):287-304

Oaxaca R. Male-female wage differentials in urban labor markets. Int Econ Rev. 1973;14:693-709.

Oaxaca RL, Ransom MR. Calculation of approximate variances for wage decomposition differentials. J Econ Soc Meas. 1998;24:55-61.

Orazem PF, Vodopivec M. Male-female differences in labor market outcomes during the early transition to market: the cases of Estonia and Slovenia. J Popul Econ. 2000;13(2):283-303.

Paci P. Gender in transition, human development unit, Eastern Europe and Central Asia region. Washington, DC: World Bank; 2002.

Parente PMDC, Santos Silva JMC. Quantile regression with clustered data. J Econometric Methods. 2016;5:1-15.

Reimers CW. Labor market discrimination against Hispanic and black men. Rev Econ Stat. 1983;65:570-9.

Reva, Anna (2010) Gender inequality in the labor market in Serbia, draft report, Poverty Reduction and Economic Management Unit, Europe and Central Asia Region Department, Washington, DC: World Bank.

Staneva A, Arabsheibani GR, Murphy P. Returns to Education in Four Transition Countries: Quantile Regression Approach. IZA Discussion Paper No. 5210; 2010.

TNS (2010) Technical report: sampling description \& quality control description, Technical Report accompanying the UNDP/UNICEF Social Exclusion Dataset 2010, Developed by TNS\Gallup Media Asia.

White $\mathrm{H}$. A heteroskedasticity-consistent covariance matrix estimator and a direct test for heteroskedasticity. Econometrica. 1980;48(4):817-30.

Winsborough HH, Dickinson P. Components of Negro-White Income Differences. Proceedings of the Social Statistics Section. 1971;6-8.

Wooldridge JM. Econometric analysis of cross-section and panel data. Second ed. Cambridge: The MIT Press; 2010.

Wooldridge JM. Introductory econometrics: a modern approach. 6th ed. Boston: Cengage; 2016.

World Bank (2010) Country data profile—at a glance, www.worldbank.org. Accessed 18 Nov 2010

Submit your manuscript to a SpringerOpen ${ }^{\odot}$ journal and benefit from:

- Convenient online submission

- Rigorous peer review

Open access: articles freely available online

- High visibility within the field

- Retaining the copyright to your article

Submit your next manuscript at $>$ springeropen.com 